\title{
The genesis of Typhoon Nuri as observed during the Tropical Cyclone Structure 2008 (TCS-08) field experiment - Part 1: The role of the easterly wave critical layer
}

\author{
M. T. Montgomery, L. L. Lussier III, R. W. Moore, and Z. Wang \\ Naval Postgraduate School, Monterey, California, USA \\ Received: 5 June 2009 - Published in Atmos. Chem. Phys. Discuss.: 16 September 2009 \\ Revised: 14 April 2010 - Accepted: 25 May 2010 - Published: 20 October 2010
}

\begin{abstract}
An observational and real-time model forecast study of the genesis of Typhoon Nuri during the Tropical Cyclone Structure 2008 (TCS-08) field campaign in the western North Pacific sector is presented. Analysis and observational data show that the surrounding base state is an easterly trade wind flow and the precursor disturbance to Typhoon Nuri is an easterly wave that originates in the ITCZ in the Central Pacific. This disturbance can be tracked more than 10 days prior to tropical storm formation. An overview of the field data is presented here using a newly proposed dynamical framework for tropical cyclone formation within the critical layer of an easterly wave. Despite propagating through a hostile environment ripe with strong vertical wind shear and relatively dry air, the easterly wave critical layer protects the protovortex and allows it to gestate until it reaches a more favorable environment. Within this protective "Kelvin cat's eye flow" located within the wave's critical layer existed a sweet spot, defined as the intersection between the wave trough and critical latitude, which is the preferred location for tropical cyclogenesis. Global Forecast System Final Analyses and IR satellite imagery, which shows convective bands wrapping around the sweet spot as genesis nears, confirm that this sweet spot is the location where Typhoon Nuri's dominant low-level circulation emerges.

United States Air Force C130 and Naval Research Laboratory P3 research flights on 16 and 17 August collected flightlevel, dropwindsonde, and Doppler radar data that allowed an evaluation of the dynamic and thermodynamic processes within the cat's eye circulation. The dropwindsonde analyses identifies the precursor easterly wave disturbance on 16 August and identifies an area of weak low-level cyclonic circulation on 17 August.
\end{abstract}

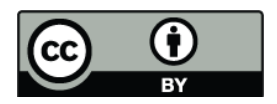

Correspondence to: $\mathrm{M}$. T. Montgomery (mtmontgo@nps.edu)
Real-time forecasts were produced using operational global prediction model data to support scientific missions during TCS-08. These forecasts were found to be useful in flight planning discussions and predicted Typhoon Nuri's eventual genesis latitude within 1.5 degrees $72 \mathrm{~h}$ in advance.

\section{Introduction}

The western North Pacific region is the most active tropical cyclone (TC) basin on the earth, responsible for, on average, 26 of the 84 named storms annually (Neumann, 1993). Numerous synoptic-scale patterns have been identified as favorable to tropical cyclogenesis over the years, including, but not limited to: Tropical Upper Tropospheric Troughs (TUTT) (e.g., Sadler, 1976, 1978), formation within a monsoon trough regime (e.g., Holland, 1995) including the special cases of monsoon depression formation (Harr et al., 1996) and monsoon gyre formation (Lander, 1994), wave energy dispersion from pre-existing depressions (Carr and Elsberry, 1995; Holland, 1995), filamentary intrusions from the subtropics (Deleon, 2008), mixed Rossby-gravity waves (Dickinson and Molinari, 2002), and easterly waves (Ritchie and Holland, 1999; Fu et al., 2007). Ritchie and Holland (1999) present a climatology of formation mechanisms in this basin and document five synoptic-scale regimes favorable to tropical cyclogenesis ${ }^{1}$. Using eight years data from the Australian Bureau of Meteorology tropical analysis scheme, they attribute $42 \%$ of the western North Pacific tropical cyclogenesis cases to monsoon shear lines, $29 \%$ to monsoon confluent regions, $18 \%$ to easterly wave disturbances, $8 \%$ to wave energy dispersion, and $3 \%$ to monsoon gyre formations. Ritchie and Holland (1999) note that these

\footnotetext{
${ }^{1}$ Ritchie and Holland (1999) define genesis as: “... the series of physical processes by which a warm-core, tropical cyclone-scale vortex with maximum amplitude near the surface forms".
}

Published by Copernicus Publications on behalf of the European Geosciences Union. 
data most likely underestimate the true number of easterly wave type formations: "development may also occur entirely in the easterly wave (18\% of cases examined here) although the sample for this pattern most probably has a low bias due to the exclusion of genesis cases near the date line". Additionally, they note: "It is difficult to distinguish between genesis in the confluence region and genesis directly from an easterly wave because of the uncertainty of when genesis processes have finished". It is possible that the easterly wave pathway to genesis is more prominent in the western North Pacific basin than Ritchie and Holland (1999) suggest. Molinari et al. (2004) examine genesis cases in the western North Pacific basin and "...believe that a significant fraction, and likely the majority, of western-Pacific tropical cyclones form in association with westward moving disturbances". Chen et al. (2008), for example, have proposed that $80 \%$ of the tropical cyclone formations in this basin are due to easterly wave ${ }^{2}$ influences either directly or indirectly (through wave-gyre interactions $)^{3}$.

Although easterly waves are ubiquitous in the trade wind region of the tropics, typically only a small percentage of these waves develop into tropical cyclones (Frank, 1970; Ritchie and Holland, 1999). Recently, Dunkerton, Montgomery, and Wang (2009; hereafter DMW09) have developed a new framework to describe the transition sequence from synoptic-scale easterly wave to tropical depression.

\footnotetext{
${ }^{2}$ In their analysis, Chen et al. (2008) did not distinguish between easterly waves and other westward propagating wave disturbances such as mixed Rossby-gravity and equatorial Rossby waves that have been shown to lead to tropical cyclogenesis in the western North Pacific (e.g., Dickinson and Molinari, 2002; Frank and Roundy, 2006). This reference nonetheless serves to illustrate that there is a school of thought that believes wave activity is more prominent in western North Pacific tropical cyclone formation (e.g., Molinari et al., 2004) than many researchers are willing to believe. While we care deeply about the different types of waves, the questions of how they lead to tropical cyclogenesis, and whether or not they can be analyzed in the marsupial framework must await future study. Nuri represents a useful and illustrative easterly wave case that represents a first step in a long process to explore the utility of the marsupial paradigm in this basin. Finally, we note that research is underway to study different types of western North Pacific waves and how the marsupial paradigm could be applied to these cases. A particularly interesting case involves Super Typhoon Manyi (2007), whose precursor disturbance was an equatorial Rossby wave and to which some of the marsupial ideas seem applicable (Lussier, 2010).

3 Chen et al. (2008) specifically use the phrase: “... monsoon gyres develop through a monsoon trough-easterly wave interaction". However, their monsoon gyre definition is not consistent with the definition provided in the Glossary of Meteorology (Glickman, 2000). Despite this non-standard terminology, the wave-gyre interaction concepts that Chen et al. (2008) present may offer useful insight into the formation process in association with easterly waves in the western North Pacific and we would be remiss not to mention it.
}

Using the National Hurricane Center best track data, National Aeronautics and Space Administration (NASA) Tropical Rainfall Measurement Mission (TRMM) data, and European Center for Medium-range Weather Prediction Forecasts (ECMWF) Reanalysis (ERA-40) data during August and September (1998-2001), they examined tropical cyclone formation from quasi-monochromatic easterly waves in the Atlantic and eastern Pacific basins and proposed a dynamical pathway to genesis that held true in 53/55 cases ${ }^{4}$.

This proposed tropical cyclogenesis sequence is centered around three new hypotheses (hereafter $\mathrm{H} 1-\mathrm{H} 3$ ) examining the flow dynamics, moist thermodynamics, and wave/vortex interactions associated with the Kelvin cat's eye flow within the critical layer of a tropical easterly wave. The cat's eye flow is hypothesized to be important to tropical storm formation because: H1) wave breaking or roll-up of the cyclonic vorticity near the critical surface in the lower troposphere provides a favorable environment for the aggregation of vorticity seedlings for TC formation; H2) the cat's eye is a region of approximately closed Lagrangian circulation, and air is repeatedly moistened by convection and protected to some degree from dry air intrusion, which favors a predominantly convective type of heating profile; and H3) the parent wave is maintained and possibly enhanced by diabatically amplified mesoscale vortices within the cat's eye. The cat's eye circulation has been shown to be the favored region of storm formation, with the eventual storm center located near the intersection of the wave's critical surface and trough axis (i.e., the "sweet spot"). This cyclogenesis sequence is likened by DMW09 to the development of a marsupial infant in its mother's pouch ${ }^{5}$ wherein the juvenile proto-vortex is

\footnotetext{
${ }^{4}$ The two remaining storms were found also to develop in a region of closed circulation when the meridional component of wave propagation is accounted for, although in one of these cases, the horizontal resolution of ERA-40 is barely adequate. For a complete definition of all technical terms used herein please consult DMW09 and the Glossary therein.

${ }^{5}$ The term "pouch" is defined in DMW09 as the flow bounded by the closed streamline that passes through the stagnation point closest to the sweet spot. The region of recirculating quasi-horizontal flow located within is the so-called Kelvin cat's eye circulation. Certain characteristics of the pouch, specifically the moisture gradient, are used here and elsewhere (Wang et al., 2009) to identify the horizontal extent and location of the pouch.

Although the Kelvin cat's eye now serves as a canonical illustration of 'anti-mixing' behavior in the two-dimensional fluid dynamics of nonlinear waves in shear flow, the concept as applied to the equivalent barotropic representation of the mid- to lowertroposphere critical layer of a tropical easterly wave is new as far as we are aware (DMW09). To sustain the required convective and mesoscale organization within, the resiliency of the wave pouch in the presence of a vertically sheared flow becomes an important problem that brings new challenges of its own (e.g., Jones, 1995; Reasor and Montgomery, 2001; Schecter et al., 2002; Reasor et al., 2004; Schecter and Montgomery, 2007; Schecter, 2008). Having said this, it must be recalled that the pouch is not decoupled from its
} 
carried along by the mother wave until it is strengthened into a self-sustaining entity.

DMW09 focus on tropical waves over the Atlantic and eastern Pacific sectors. The data collected during Tropical Cyclone Structure 2008 (TCS-08), a field campaign that took place from August-September 2008 over the western North Pacific, provides a unique opportunity to test the "marsupial paradigm" for easterly wave scenarios in a different basin. The overall objectives of TCS-08 are to develop a better understanding of storm-scale processes in the western North Pacific associated with tropical cyclones and to further the understanding of interactions between convective processes and tropical cyclone genesis, structure/evolution, intensity, and predictability (Elsberry and Harr, 2008). To accomplish these objectives, a multi-platform observing strategy was implemented. Both United States Air Force (USAF) C130 Hurricane Hunter aircraft [providing dropwindsondes, flight-level data, Stepped Frequency Microwave Radiometer (SFMR) data, and the ability to drop both Airborne Expendable Bathometry Thermographs (AXBT) and ocean buoys] and the Naval Research Laboratory (NRL) P3 aircraft [fitted with the Electra Doppler Radar (ELDORA), dropwindsonde capability, a Doppler wind lidar, and the ability to collect flight-level data] flew aircraft research missions originating from Guam, a USA territory. For further information on the observing strategies and scientific objectives of TCS-08, see Elsberry and Harr (2008).

Typhoon Nuri was the first tropical cyclogenesis event occurring within aircraft observational range $(\sim 3000 \mathrm{~km})$ during TCS-08. The storm was flown on four consecutive days (16-19 August) by the USAF C130, enabling the documentation of the evolution from easterly wave through Category 2 typhoon. The NRL P3 flew concurrently with the C130 on three days (16-18 August), enabling a documentation of the mesoscale and convective structure during the transition from easterly wave to tropical storm (TS) intensity.

The goal of this first study is to examine the genesis of Typhoon Nuri from the easterly wave precursor and provide a first test of the marsupial paradigm in the western North Pacific basin. This test is comprised of two parts: a postanalysis of a portion of the data collected during TCS-08; and an evaluation of the real-time 'marsupial forecasts' for

parent easterly wave and it would be incomplete to view the pouch as an isolated vortex. Resilience and vertical coherence of the pouch are nonetheless thought to have important ramifications on the ensuing moist thermodynamics within. A horizontally and vertically resilient pouch serves to protect the middle levels from dry air intrusions. It also serves to accumulate mid-level moisture lofted by deep convection. Both effects are believed to mitigate the deleterious effects of downdrafts and the importation of low equivalent potential temperature into the marine boundary layer. In Sect. 3.2, we examine the time evolution of the depth of pre-Nuri's wave pouch as one measure of its vertical coherence during an episode of strong vertical wind shear. Additional discussion is provided in our response to an Interactive Comment.
Typhoon Nuri that were produced and used as guidance for operational decisions during the TCS-08 field program.

The outline of the manuscript is as follows. Section 2 describes the data and methodology used. Section 3 examines the results obtained from analysis of the observational and forecast data. Section 4 discusses the genesis of Typhoon Nuri in the context of real-time forecasting. Section 5 summarizes the results presented in this paper and outlines our planned next steps for analysis of this storm.

\section{Data and methodology}

\subsection{Data}

Multiple datasets are used in this research: 1) Six-hourly GFS Final Analyses (GFS FNL) and forecast data, projected onto a one degree grid; 2) Multi-Functional Transport Satellite (MTSAT) half-hourly infrared (IR) satellite data at 4-km resolution; 3) Joint Typhoon Warning Center (JTWC) Best Track Data; 4) USAF C130 and NRL P3 dropwindsonde data; 5) Naval Operational Global Atmospheric Prediction System (NOGAPS) and ECWMF analyses and forecast data; 6) QuikSCAT surface wind data; and 7) Cooperative Institute for Meteorological Satellite Services (CIMSS) satellite products. Not all of these data are independent. Specifically, the JTWC Best Track Data relies heavily on the MTSAT satellite imagery and aircraft observations for position fixes, and both numerical models assimilated the in-situ aircraft observations and satellite observations into their analyses.

\subsubsection{Summary of aircraft missions}

Aircraft dropwindsonde data from the USAF C-130 and NRL P3 over two days (16-17 August) prior to TS declaration are evaluated herein. Figure 1 provides a summary of the key events in the genesis sequence of Typhoon Nuri. In the preTyphoon stage, the USAF C130 operated at $31000 \mathrm{ft}$ to provide extensive vertical profiles of the atmosphere. Its primary missions were to provide synoptic and mesoscale analysis of the developing system, locate a developing circulation center, and direct the NRL P3 to mesoscale areas of interest. The primary mission of the NRL P3 was to use the ELDORA to sample the convection within the marsupial "pouch"4 of the parent wave disturbance, with secondary missions of providing dropwindsonde and flight-level data coverage. While on station, the NRL P3 typically flew at altitudes of 8000$12000 \mathrm{ft}$.

During the 16 August flight, the USAF C130 flew in a socalled "lawn-mower" pattern (Fig. 2 top), centered on $147 \mathrm{E}$, and oriented along the axis of the easterly wave trough. Deviations were made to the pattern during flight to better sample the western edge of the wave as it was propagating faster than forecast and to the southern edge of the wave where the convection was most vigorous. The second C130 mission (17 


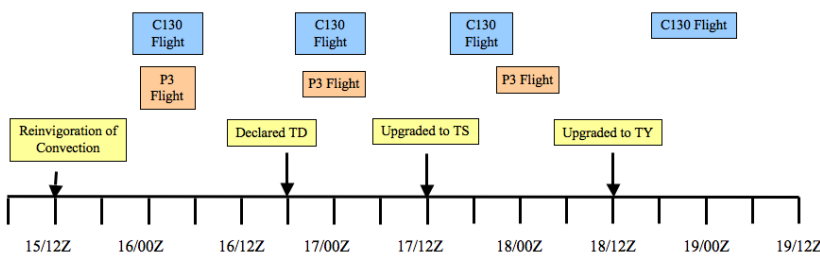

Fig. 1. Timeline of key events during the observational period of Typhoon Nuri during the TCS-08 field experiment between 12:00 Z 15 August and 12:00 Z 19 August 2008.

August) flew a so-called "square spiral" pattern (Fig. 2 bottom) centered on $14 \mathrm{~N}, 142 \mathrm{E}$, the intersection of the wave trough and the critical latitude derived from NOGAPS model forecast data. In-flight deviations were made to this pattern as a low-level circulation was identified by dropwindsonde data in the southwestern corner of the pattern.

The first NRL P3 flight (16 August) focused on the convective process occurring near the potential sweet spot as identified by the NOGAPS forecast. Toward the end of its mission, the aircraft climbed to flight levels greater than $20000 \mathrm{ft}$ to provide dropwindsonde coverage on the extreme western edge of the wave, which was not covered by the C130. The second NRL P3 flight (17 August) began as a rectangular pattern within the square spiral of the USAF C130 pattern. Its mission was to provide a statistical sample of the convection within the wave's pouch, therefore, multiple passes on convective cells were not made in order to obtain an unbiased sample.

\subsection{Analysis methodology}

Marsupial analysis and forecast products are produced using the following methodology:

\subsubsection{GFS FNL}

For GFS FNL analyses, the maximum latitudinally-averaged $(9-17 \mathrm{~N})$ total precipitable water (TPW) is used for both wave tracking and to calculate wave phase speeds. This methodology has three significant advantages: i) it allows tracking of moisture in two dimensions, rather than simply the moisture at the latitude of the sweet spot; ii) it results in a stronger pouch signal if there is not strictly westward translation; and iii) it allows for wave tracking when the moisture gradient is not as obvious, such as in the relatively moist region of the western North Pacific. Disadvantages of this methodology are evident when the pouch and/or the distribution of moisture within are not symmetric or the wave is relatively dry. This situation results in a weaker TPW signature since the potential for dry air on the outskirts of the wave pouch tends to be included in this average value. For the Nuri case, the advantages of the latitudinal averaging outweigh these disadvantages.
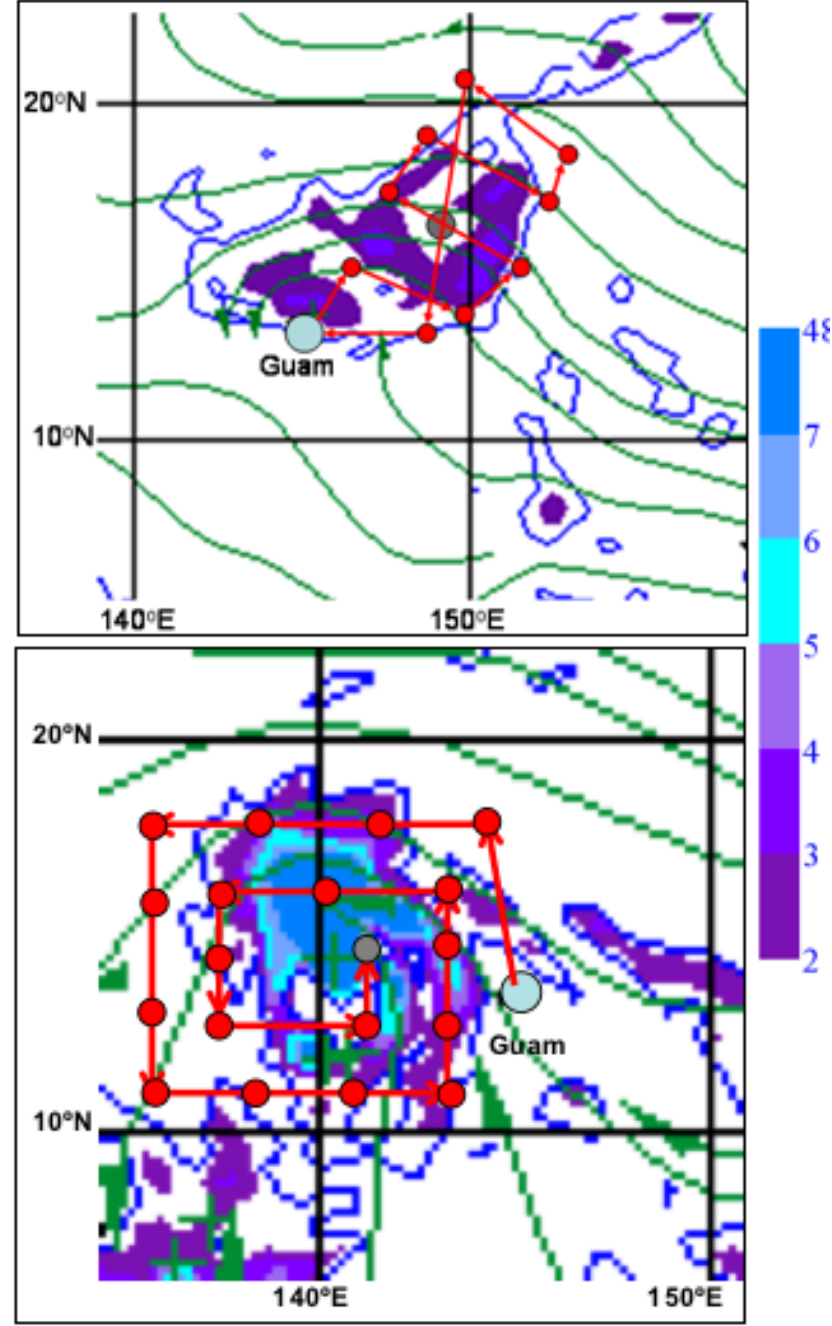

Fig. 2. Schematic of original flight plans for the USAF C130 flights centered on 00:00 Z 16 August (top) and 00:00 Z 17 August (bottom). The green lines are $850 \mathrm{hPa}$ streamlines in the resting frame and the shading is relative vorticity $\left(\times 10^{5} \mathrm{~s}^{-1}\right)$ derived from ECMWF forecast data. The large blue circles indicates Guam, the smaller gray circles highlight the predicted sweet spot position, and the red circles indicate locations where dropwindsondes were released. The streamline analysis clearly depicts the presence of an open wave (top) approaching Guam. The red lines highlight the "lawn-mover" pattern that was centered on the sweet spot. In the bottom panel, the "square spiral" pattern used during the second mission has the USAF C130 spiraling inward toward the forecasted sweet spot position.

Once the zonal phase speeds are calculated, a streamline analysis in the co-moving frame is produced. The critical latitude is defined as the latitude at which zonal velocity equals the zonal phase speed, i.e., $u=C$; the trough axis is defined as the locus for which the meridional velocity vanishes, i.e., $v=0$ and the relative vorticity is cyclonic (DMW09 and 
Wang et al., 2009; hereafter WMD09). The intersection of the critical latitude and the trough axis in the lower troposphere pinpoints the sweet spot.

\subsubsection{Real-time "marsupial forecasts"}

WMD09 demonstrated that the preferred location for tropical cyclogenesis could be predicted within $200 \mathrm{~km}$ up to $72 \mathrm{~h}$ in advance using operational numerical models. For GFS and NOGAPS marsupial forecasts produced during TCS-08, an average phase speed was derived from Hovmoeller diagrams using three meteorological variables to minimize errors arising from individual tracking methods: i) a zonal phase speed is calculated using the zero contour line in the meridional wind field. For real-time forecasts with no filtering, the wave signal in the meridional wind field is noisier because of high frequency variations and/or short-lived mesoscale vortices within the pouch (WMD09). ii) A phase speed based on local fluid rotation is calculated using either relative vorticity or Okubo-Weiss $(\mathrm{OW})$ as defined in DMW09 $\left(O W=\zeta^{2}-S_{1}^{2}-S_{2}^{2}\right)$; where $\zeta$ is relative vorticity, $S_{1}$ is the stretching deformation, and $S_{2}$ is the shearing deformation). This has limitations in the cases of tracking weak waves where the rotational signature has yet to strengthen. iii) A phase speed based on the tracking of a zonal moisture gradient: TPW for GFS and relative humidity for NOGAPS (WMD09). The TPW signature is observed to be one of the most reliable pouch tracking methodologies in the Atlantic (WMD09); however, the zonal gradient of TPW is much weaker in the western North Pacific basin as much of this region is persistently moist barring dry air outbreaks from east Asia.

For real-time forecasting during TCS-08, these three phase speeds typically show little difference. Generally, differences are within $1 \mathrm{~m} \mathrm{~s}^{-1}$ (DMW09 show that the pouch center is usually not sensitive to $1-2 \mathrm{~m} \mathrm{~s}^{-1}$ errors in the phase speed; however, the separatrix orientation may be sensitive to these small changes in the phase speed). The major difference between the tracking techniques lies in the relative strength of each signal. The real-time tracking parameter that appears to offer the most potential is TPW. This would be the variable of choice for the following reasons: i) it offers the most robust signal in real-time (especially in the Atlantic); ii) since it is a vertically integrated property, the need to select a level for evaluation is removed; and iii) it is observed by satellite and thus observations could be used in real-time versus analysis or forecast data.

Diagnostic output of pertinent field variables is presented as vertical cross-sections after averaging each variable horizontally within a $3^{\circ} \times 3^{\circ}$ box centered on the sweet spot (Montgomery et al., 2010; Wang et al., 2010a, b). These diagnostics are considered as an approximate representation of the pouch evolution. Examples of variables used in vertical cross-sections include relative vorticity, OW, and detrained volume flux $(\Delta)$, which is calculated at each level according to:

$\int_{A}\left(\frac{\partial u}{\partial x}+\frac{\partial v}{\partial y}\right) d A$

where $u$ denotes zonal velocity, $v$ the meridional velocity and dA is the horizontal area element (Raymond et al., 1998).

\section{Results}

\subsection{Evolution of the easterly wave precursor (12:00 Z 7 August - 00:00 Z 10 August)}

Although the ultimate origin of the pre-typhoon Nuri disturbance is beyond the scope of this paper, the CIMMS morphed TPW analysis (Fig. 3) suggests that it originated from a "roll-up" episode in the central Pacific Inter-tropical Convergence Zone (ITCZ) on 12:00 Z 7 August. At this time the GFS FNL first identifies a low-level ${ }^{6}$ southwest-northeast tilted easterly wave in the streamline analysis centered at $8 \mathrm{~N}$, 165E (not shown). The vorticity and moisture fields associated with the easterly wave are disorganized. Whether this roll-up is caused by an underlying hydrodynamic instability of the ITCZ (Ferreira and Schubert, 1997; Wang and Magnusdottir, 2006) or a nonlinear evolution of a nearly-neutral moist Rossby wave/vortex on the northern side of the ITCZ (DMW09) is unknown and beyond the scope of the current investigation. For the purposes of this study, we accept the existence of this finite-amplitude wave/vortex structure that can be tracked westward for ten days prior to the declaration of Tropical Storm Nuri.

Figure 4 depicts a GFS FNL Hovmoeller diagram of latitudinally-averaged TPW valid from 00:00 Z 6 August until 12:00 Z 17 August. A wave signal (indicated by a region of higher TPW) is first evident in these data at 00:00 Z $8 \mathrm{Au}-$ gust. This signal is tracked coherently from this time until the TS stage is declared by the JTWC forecasters (12:00 Z 17

\footnotetext{
${ }^{6}$ For the analyses presented in this paper, low-level refers to levels below $850 \mathrm{hPa}$. The maximum amplitude of the easterly waves observed during TCS-08 was usually lower than what is typically observed in the Atlantic sector. This is consistent with Reed and Recker (1971) and Chang et al.'s (1970) findings, and is the primary reason why we present analyses at levels below $850 \mathrm{hPa}$ rather than the original DMW09 methodology. In an operational setting, the optimal level at which to apply the marsupial analysis tools is determined upon consideration of the underlying structure of the precursor wave disturbance. For the western North Pacific cases evaluated during TCS-08 (including Typhoon Nuri), the easterly waves had their maximum amplitude in the lower troposphere (at or below $850 \mathrm{hPa}$ ). Operational analyses using the maruspial framework in the eastern Atlantic for example would focus on levels higher in the troposphere (e.g., WMD09) due to the observed characteristics of typical African Easterly Wave precursors. Other real-time issues that arise in an operational application of the theory presented herein are elaborated in our response to an Interactive Comment.
} 


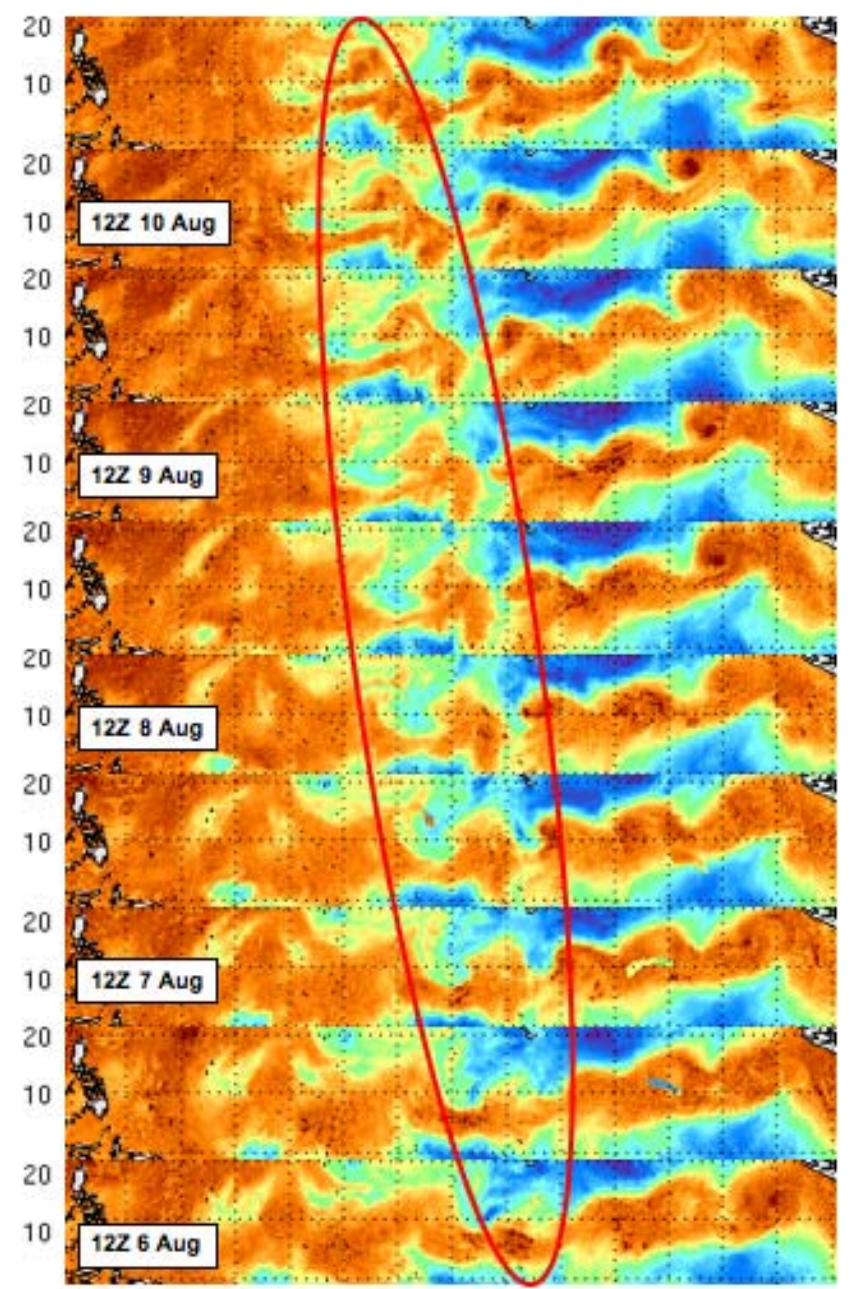

$130140150160170180-170-160-150-140-130-120-110$

Fig. 3. CIMMS Morphed TPW time series valid at 12-h intervals beginning at 12:00 Z 6 August. The red oval highlights the ITCZ roll-up event that is proposed to be the origin of the pre-Nuri disturbance.

August). Due to the extended period that this wave is tracked, the wave is not expected to maintain a constant phase speed throughout its lifecycle. Observed changes in propagation speed are attributed to synoptic-scale regime changes or variations in the vertical level of the maximum amplitude of the wave over time. Two distinct regimes are identified here and a zonal phase speed for each is calculated using the GFS FNL TPW Hovmoeller diagrams. The first time period lasts from 12:00 Z 7 August-00:00 Z 11 August and is accompanied by a higher zonal phase speed $\left(-10.5 \mathrm{~m} \mathrm{~s}^{-1}\right)$. As the wave crosses the dateline, it enteres a region of weaker synoptic-scale steering flow, which causes the phase speed of the wave to gradually decrease. The average wave phase speed over the later period (06Z 11 August-12:00 Z $17 \mathrm{Au}$ gust) is $-7.0 \mathrm{~m} \mathrm{~s}^{-1}$. The evolution of the wave's phase speed, including the slowing down as the system moves westward,

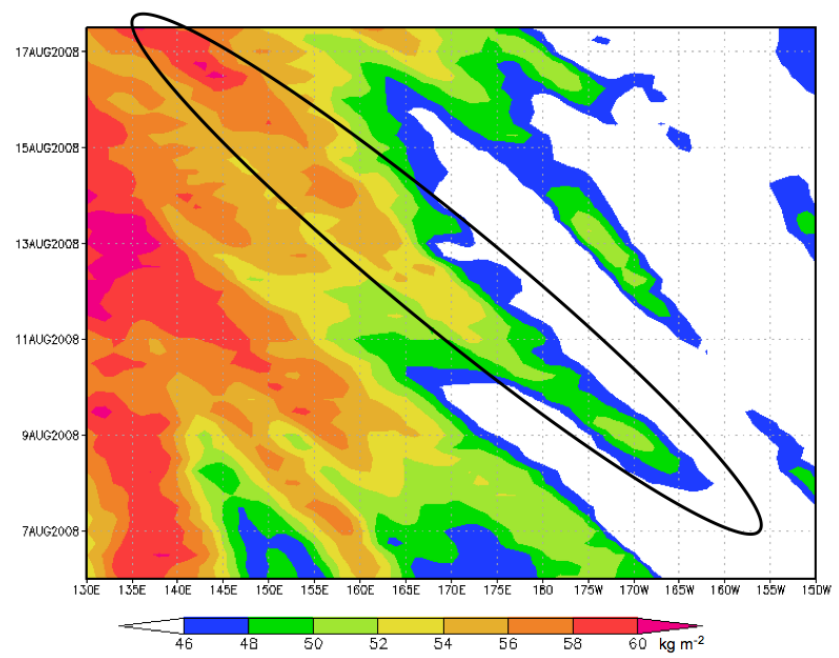

Fig. 4. Latitudinally-averaged (9-17N) GFS FNL TPW Hovmoeller valid 00:00 Z 6 August-12:00 Z 17 August (the time when the precursor Nuri disturbance is upgraded to a TS). The black oval highlights the higher moisture content observed in the pouch of the pre-Nuri disturbance versus its surrounding environment.

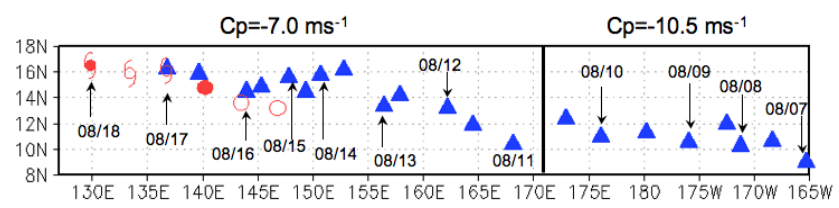

Fig. 5. GFS FNL location of the sweet spot (blue triangles) valid at 12-h intervals from 12:00 Z 7 August-12:00 Z 17 August. The thick line delineates the time of the change in phase speeds used to calculate the sweet spot location. JTWC Best track positions are indicated (red) at 12-h intervals beginning at 00:00 Z 16 August. An open circle designates an invest and a closed circle a TD. TS and typhoon symbols are shown when storm upgrades occurred.

are consistent with the propagation speed of easterly waves observed by Serra et al. (2008) in the central/western North Pacific sectors.

These phase speeds are used with the GFS FNL to construct an 'official' track of the sweet spot associated with the easterly wave that formed Typhoon Nuri. Figure 5 displays the location of the sweet spot (solid blue triangles) at the $925 \mathrm{hPa}$ level at 12-h intervals from 12:00 Z 7 August12:00 Z 17 August, together with the JTWC Best Track position beginning at 00:00 Z 16 August (red symbols). While the initial sweet spot of the wave trough is at approximately $10 \mathrm{~N}$, it propagates steadily westward and gradually northward, remaining between $14.5-17 \mathrm{~N}$ from 14 August onward. The slight southward movement of the sweet spot on $16 \mathrm{Au}-$ gust is believed to be due to the shift of the critical latitude southward as a response to the strong convective activity observed by both satellite and aircraft radar data in the southern quadrant of the wave's pouch. 


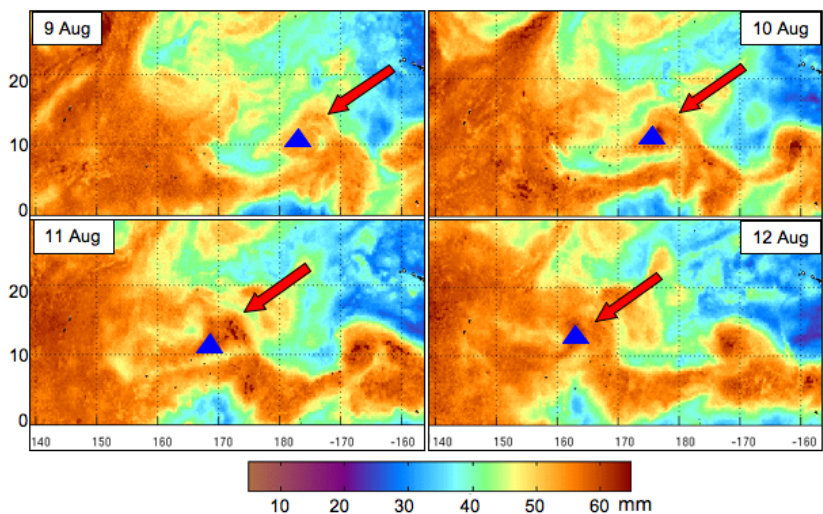

Fig. 6. Four-day time series of CIMMS Morphed TPW valid at 12:00 Z each day. Red arrows point towards the cat's eye region of the easterly wave (i.e., the wave pouch), which is hypothesized by DMW09 to be an area of increased moisture in the low to midtroposphere and which helps protect the proto-vortex from lateral intrusions of dry air. The blue triangles indicate the position of the sweet spot as diagnosed in the GFS FNL at the $925 \mathrm{hPa}$ level.

During the early evolution of this disturbance, a closed low-level cyclonic circulation is evident in the co-moving frame from 00:00Z 8 August until 00Z 12 August. Values of OW within the pouch increase steadily (not shown) prior to the wave crossing the dateline (00:00 Z 10 August). This is indicative of the disturbance showing favorable characteristics for tropical cyclogenesis (consistent with WMD09). Adverse environmental conditions during 10-14 August (discussed below) are argued to prevent genesis during this time.

\subsection{Maintenance of the pouch through a hostile environment (12:00 Z 10 August-00:00 Z 15 August)}

Gray $(1968,1975)$ introduces a set of necessary conditions for tropical cyclogenesis that remain generally accepted today. Here, they are summarized into the following four conditions: i) sea-surface temperatures $>26^{\circ} \mathrm{C}$; ii) weak 850 $200 \mathrm{hPa}$ vertical wind shear; iii) sufficient cyclonic vorticity in the lower troposphere; and iv) moist convective instability and a moist mid-troposphere. This section focuses on the period from 12:00 Z 10 August-00:00 Z 15 August, a time when these favorable conditions generally are not satisfied. It is suggested that this hostile synoptic environment has a profound influence on the evolution of the pre-Nuri disturbance.

As the pouch crosses the dateline, its translation takes on a northward component, which results in a displacement of the sweet spot from $10 \mathrm{~N}$ to $15 \mathrm{~N}$ over the next five days (consistent with the motion of western North Pacific easterly waves observed by Serra et al 2008). Concomitantly, the wave's pouch enteres a region with relatively dry low-mid level air and strong vertical wind shear, conditions that are widely accepted to be particularly hostile to tropical cyclone forma-

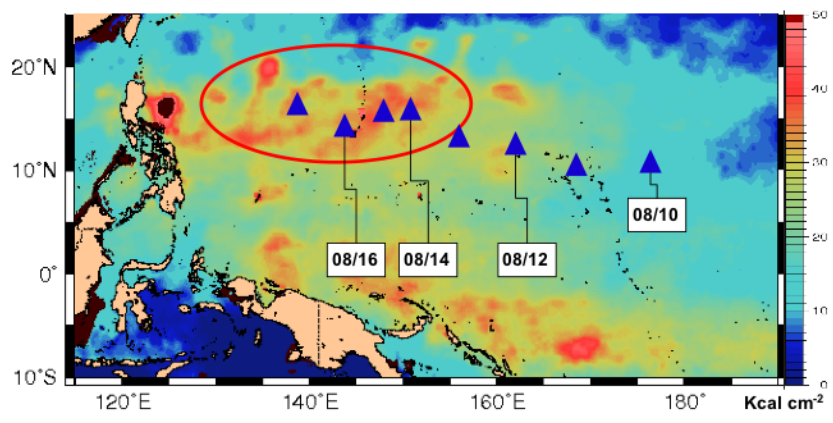

Fig. 7. NRL Stennis oceanic HHC analysis valid 12:00 Z 15 August overlaid with the track of the sweet spot from the GFS FNL analyses (solid blue triangles). The red oval indicates the area of higher HHC that the pouch passes over from the time convection is reinvigorated (12:00 Z 15 August) until a tropical storm is declared.

tion. Figure 6 displays a times series of the CIMMS Morphed TPW product valid at 12:00 Z each day over a four-day period (9-12 August). The first panel shows the moist pouch of the pre-Nuri disturbance as an area of higher TPW centered at $10 \mathrm{~N}, 175 \mathrm{~W}$ on 9 August. This relatively moist pouch is: i) surrounded on three sides by drier air, with only the air in the south to southeast sector being moist (consistent with DMW09), and ii) disconnected from the moist air in the western North Pacific. The pouch signal (identified as the area of relatively higher moisture) is more evident $24 \mathrm{~h}$ later (10 August) when the pre-Nuri pouch $(11 \mathrm{~N}, 177 \mathrm{E})$ takes on the shape of an elongated oval of higher moisture and relatively drier air remains to the north through west and southern quadrants, upstream of the pouch.

On 11 August (Fig. 6), the moist air associated with the pouch $(12 \mathrm{~N}, 172 \mathrm{E})$ has propagated west and has begun to link with the moist air in the western North Pacific. There remains an area of relatively drier air separating this feature from the main pool of western North Pacific moisture. Furthermore, the pouch continues to exhibit higher TPW than its surrounding environment, and the TPW within the pouch has increased over time. This supports DMW09's second hypothesis $(\mathrm{H} 2)$ that the marsupial pouch tends to protect the seedling embryo from the lateral intrusion of dry air. By 12 August (Fig. 6), the moist pouch has almost entirely merged with the western North Pacific moisture pool. The moisture content within the pouch $(12 \mathrm{~N}, 162 \mathrm{E})$ remains higher than the ambient environmental moisture. A small amount of relatively drier air remains to the west, still separated from this moist air-mass feature.

During the time period 9-13 August the wave's presence in an area of low oceanic hurricane heat content $(\mathrm{HHC})^{7}$ is

\footnotetext{
7 The NRL HHC plots use the definition presented in Leipper and Volgenau (1972), who define HHC as the integrated heat content down to the $26 \mathrm{C}$ isotherm relative to water of $26 \mathrm{C}$ : $\mathrm{HHC}=\int \rho C_{p} \Delta T \Delta Z$ for $z>$ Z26. Here $\rho$ is the density of ocean water near the mixed layer region, $C p$ is the specific heat of ocean
} 
an inhibiting factor to the development of deep convection and tropical cyclogenesis. Figure 7 shows the NRL Stennis HHC analysis for 12:00 Z 15 August with the sweet spot track overlaid (solid blue triangles). As oceanic heat properties evolve slowly (time scale of weeks to months), this figure is representative of conditions over this time period. The motion of the wave pouch from 10-13 August places it over an area of lower HHC, which tends to reduce the convective available potential energy. This reduction in $\mathrm{HHC}$ results in a somewhat reduced equivalent potential temperature of the boundary layer air, which in turn tends to effectively stabilize the lower troposphere and thereby inhibit deep convection. This is known to be unfavorable for tropical cyclogenesis. After 12:00 Z 14 August, the wave pouch moves into a region of higher $\mathrm{HHC}$, which is favorable for tropical cyclogenesis.

Another factor inhibiting tropical cyclogenesis during this time period is strong vertical wind shear. Figure 8 shows a six panel time series of deep layer $(200-850 \mathrm{hPa})$ shear and $925 \mathrm{hPa}$ streamlines in the co-moving frame from the GFS FNL valid at 12:00 Z each day from 10-15 August (the solid blue triangle indicates the position of the sweet spot). On 10 August, a closed low-level cyclonic circulation has just crossed the dateline and is entering an unfavorable area shear of deep layer vertical shear greater than $21 \mathrm{~m} \mathrm{~s}^{-1}$ (40 kt). Over the next $24 \mathrm{~h}$, the areal extent of the strongest vertical wind shear $\left(>21 \mathrm{~m} \mathrm{~s}^{-1}\right)$ decreases and shifts to an area between $160-170 \mathrm{E}$ and $12-18 \mathrm{~N}$. This strong vertical is believed to have contributed to the weakening circulation observed on 11-12 August. By 12:00 Z 12 August, the closed circulation in the co-moving frame is no longer evident. During the next two days (13-14 August), the area of strongest shear $\left(>21 \mathrm{~m} \mathrm{~s}^{-1}\right)$ is observed to retreat eastward and, as a result, the precursor disturbance encounters a less hostile environment. After 12:00 Z 14 August, the pouch of the pretyphoon Nuri disturbance enters and remains in a region of $2.5-5.1 \mathrm{~m} \mathrm{~s}^{-1}(5-10 \mathrm{kt})$ of vertical shear until genesis.

The vertical depth of the wave pouch is examined during Typhoon Nuri's genesis sequence to assess the potential effects this vertical wind shear may have on pouch resiliency. For this exercise, the depth of the pouch (i.e., vertical extent) is defined as the upper-most level at which the areally-averaged OW remains positive (the averaging domain is a $3^{\circ} \times 3^{\circ}$ box surrounding the translating sweet spot at the $925 \mathrm{hPa}$ level). These data are plotted as vertical extent vs. time (Fig. 9) and the three phases of the tropical cyclogenesis sequence described in this section are delimited by thick black lines. During the early evolution period (12:00 Z 7 August-00:00 Z 10 August) the pouch exhibits a trend of increasing vertical depth over time. After 12:00 Z $10 \mathrm{Au}-$ gust, when the wave propagates through the hostile environment, there is a decline in the average vertical extent of the

water at constant pressure near the mixed layer region, $\Delta T$ is the average temperature difference above $26 \mathrm{C}$ for a given depth increment, and $\Delta Z$ is the incremental depth (taken at $0.5 \mathrm{~m}$ ). pouch. When the wave emerges from these hostile conditions (00:00 Z 15 August) there is a rapid increase in the vertical extent of the pouch through the troposphere. These data suggest that the hostile conditions encountered by the preNuri wave are not favorable for building a coherent circulation throughout the depth of the troposphere. The increase in vertical depth of the wave pouch is thought to be a favorable condition for genesis and appears to have occurred in the Typhoon Nuri case.

\subsection{Reinvigoration of convection and initiation of the genesis sequence (12:00 Z 15 August-12:00 Z 17 August)}

Figure 10 depicts a times series of $925 \mathrm{hPa}$ streamlines from the GFS FNL in the resting frame valid at 12-h intervals from 12:00 Z 15 August-12:00 Z 17 August. Figure 11 shows the corresponding time series in the co-moving frame. Overlaid on these figures are MTSAT IR brightness temperature data. The images in the co-moving frame show the wave trough axis (black line) and critical latitude (purple line). The thick black line is the approximate track of the sweet spot center. On 12:00 Z 15 August, strong convection begins to form on the eastern and southern portions of the wave trough (Fig. 10 , when viewed in the resting frame) or pouch (Fig. 11, when viewed in the co-moving frame) as it has moved into an environment of low vertical wind shear (Fig. 8) and higher HHC (Fig. 7). A closed low-level cyclonic circulation is evident in the co-moving frame. Interestingly, this is not evident in the ground-based reference frame and is consistent with DMW09 who note that a closed circulation can be found in the co-moving frame up to $72 \mathrm{~h}$ earlier than in the groundbased reference frame.

The second panels of figures 10 and 11 are valid during the first joint USAF C130/NRL P3 flights into the pre-Nuri disturbance (00:00 Z 16 August, see Fig. 1). The intersection of the critical latitude and wave trough is at $14.9 \mathrm{~N}, 145.3 \mathrm{E}$. The strongest convection at this time is located to the south and east of the sweet spot, but it remains largely within the pouch. This is consistent with DMW09, who argue that repeated convection within the pouch leads to continued moistening, favoring further deep convection, resulting in an important positive feedback process. The southern and eastern portions of the wave pouch are the favored regions for convection at this time, most likely because of their location in an area of higher HHC.

The C130/P3 research missions centered on 00:00 Z 16 August sampled the horizontal extent of the pouch. Figure 12 depicts the dropwindsonde data from these flights overlaid with MTSAT IR data. The top panel represents $850 \mathrm{hPa}$ wind barbs in the resting frame and the bottom panel shows the data in the co-moving frame. The red cross is the location of Guam. The blue triangle indicates the approximate location of the dropwindsonde-derived closed low-level cyclonic circulation in the co-moving frame. When viewed in 


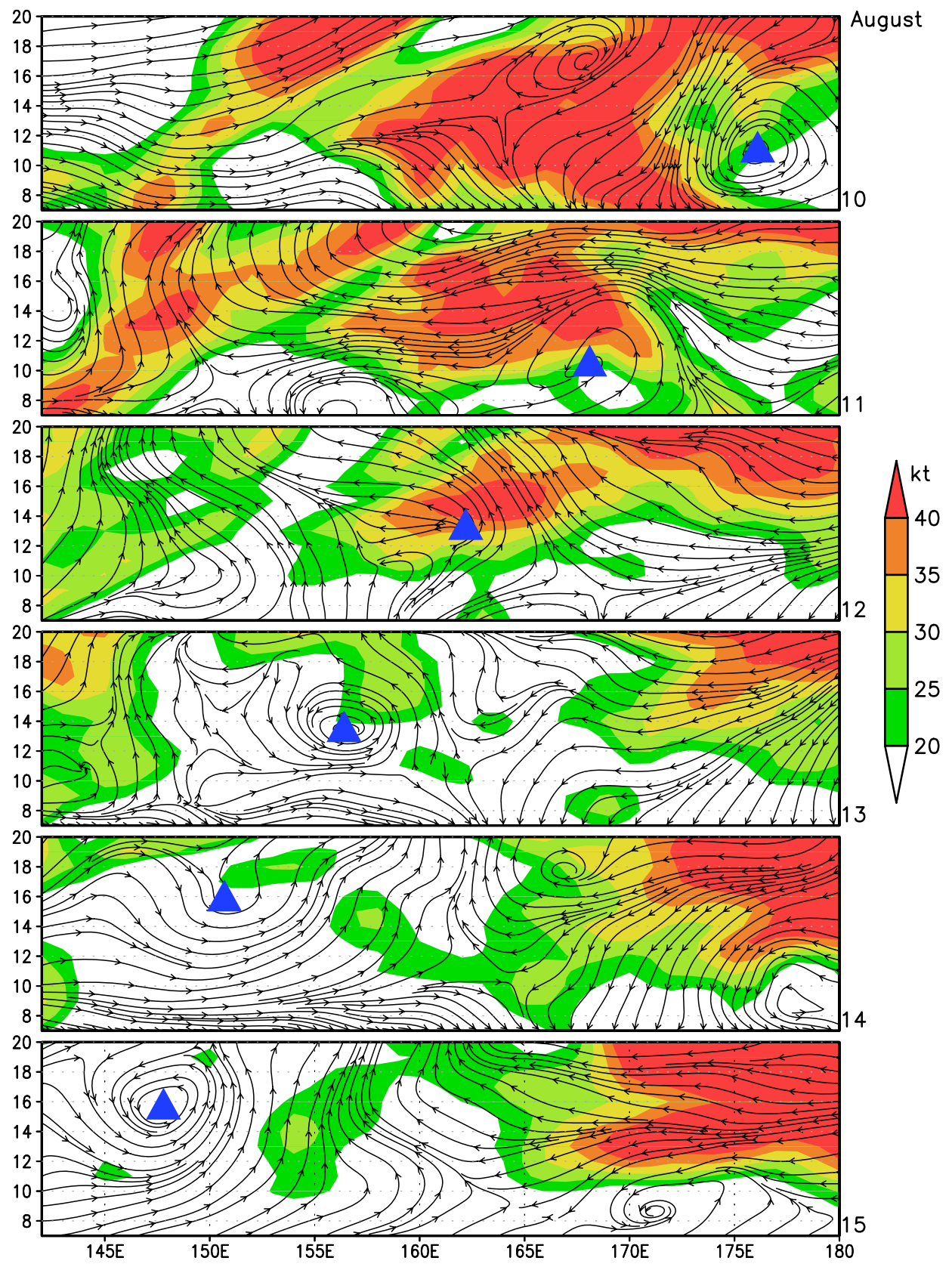

Fig. 8. GFS FNL 850-200 hPa vertical shear (in kt, shaded), $925 \mathrm{hPa}$ streamlines in the co-moving frame, and sweet spot location (solid blue triangles) valid at 12:00 Z each day.

the earth-relative frame the aircraft observations depict an open wave ${ }^{8}$, confirming that the precursor disturbance to Ty-

\footnotetext{
${ }^{8}$ Confusion has arisen in the interpretation of this figure because of the two light ( $<2 \mathrm{kts}$ magnitude) wind barbs in the southwestern quadrant of the image. Without looking at the raw data, these two wind barbs appear to form a closed circulation in the resting frame. However, examination of the raw data indicates that that the wind observation at $12.5 \mathrm{~N}, 144.5 \mathrm{E}$ is flow from the south-southeast and the wind barb located near $11.8 \mathrm{~N}, 145 \mathrm{E}$ is indicative of southeasterly flow. To be clear, at the $850 \mathrm{hPa}$ level the dropwindsonde data
}

phoon Nuri is of the easterly wave type. In the co-moving frame, the dropwindsonde data (Fig. 12) indicates a closed low-level cyclonic circulation at 146.7 E, 14.3 N. We believe this to be the first in-situ observational evidence of the coherent cat's eye circulation that gave birth to the formation of Typhoon Nuri.

suggest no indication of a closed circulation in the resting frame and none of the wind barbs have a westerly wind component. 


\section{Depth of Positive OW}

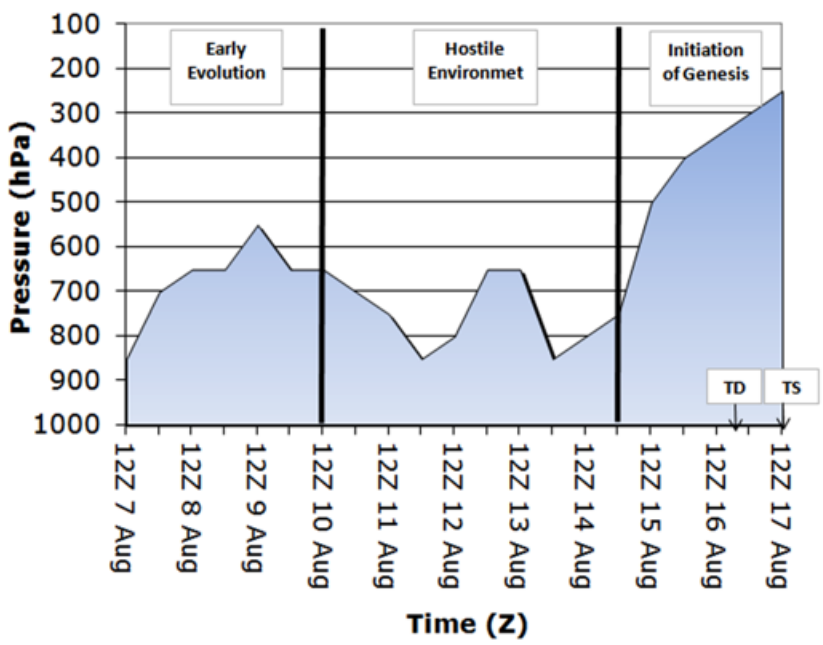

Fig. 9. Time series of depth of areally-averaged positive OW (shaded) over time from the GFS FNL. The OW is areally averaged within a $3^{\circ} \times 3^{\circ}$ box centered on and moving with the sweet spot at the $925 \mathrm{hPa}$ level as discussed in Sect. 3.2. The depth of positive OW is considered an estimate of the vertical depth of the pouch. The thick black lines delimit key time periods in pre-Typhoon Nuri's evolution as described in this study. TD and TS indicate JTWC upgrades of the storm.

The GFS FNL/MTSAT analysis valid at 12:00 Z $16 \mathrm{Au}-$ gust (middle panels, Fig. 10 and 11) depicts a closed lowlevel cyclonic circulation in both reference frames. However, the center of this cyclonic circulation in the resting frame is located more than one-degree south of the circulation in the co-moving frame. It is noteworthy that the convective maximum was located west of the trough axis. The shifting of the precipitation maximum from east of the trough axis to the west as the wave moves to the west is consistent with previous studies on western North Pacific easterly waves dating back to Reed and Recker (1971). Figure 13 is a zoomed-in view of this time period; strong convection beginds to occupy all quadrants of the pouch and is beginning to become centered on the sweet spot. Of particular interest is the initiation of convective bands to the south and northeast of the sweet spot (red arrows), which satellite loops show to spiral cyclonically inward towards the center of the circulation in the co-moving frame. At the time of the second joint USAF C130/NRL P3 sortie into the pre-Nuri disturbance (00:00 Z 17 August), convection has filled all quadrants of the wave's pouch and the banding seen 12-h earlier is even more evident (Figs. 10 and 11). These observations suggest that deep convection is beginning to wrap around the low-level cyclonic circulation center in the co-moving frame as the system is undergoing tropical cyclogenesis (JTWC upgraded this invest area ${ }^{9}$ to a TD prior to this time, Fig. 1).

\footnotetext{
9 The term "invest" is used by operational tropical cyclone fore-
}

The second C130 flight identifies a broad cyclonic circulation center at $850 \mathrm{hPa}$ in the southwestern portion of the flight pattern at approximately $14 \mathrm{~N}, 139.5 \mathrm{E}$ (Fig. 14). This circulation center is observed to tilt with height and was weak and shallow. The area where this cyclonic circulation was observed is concurrent with the areas of strongest convection (Fig. 10) and is consistent with the closed low-level cyclonic circulation in the GFS FNL resting-frame analysis (Fig. 10). In the co-moving frame, however, the low-level cyclonic circulation is slightly farther east (140.5 E) and north $(15 \mathrm{~N})$ of the circulation center in the resting frame. In this co-moving frame, the circulation is well defined and more robust than the weakly observed circulation in the resting frame. This suggests that the flow pattern in the co-moving frame is more representative of the intrinsic atmospheric state (developing TD) than the chaotic flow observed in the resting frame. This analysis illustrates the inherent benefit of viewing/tracking a developing tropical cyclone in the co-moving frame (as advocated in DMW09) for operational forecasters.

\subsection{Consideration of other possible factors in the formation of Typhoon Nuri}

\subsubsection{The possible role of a monsoon trough}

In the case of Typhoon Nuri, the presence of near equatorial westerlies near Palau (7 N, 134E) has been cited by other TCS-08 researchers as evidence of the influence of a monsoon trough leading to genesis of this Typhoon Nuri within this easterly wave (versus the non-development of previous easterly waves observed during TCS-08). The following analyses show that the westerly flow near Palau: i) is not indicative of the presence/formation of a monsoon trough influencing Typhoon Nuri's genesis region; and ii) has no discernible impact on the formation of Typhoon Nuri.

Analysis of vertical wind profile derived from Skew-T data (not shown) shows weak westerly flow (5-15 kt) in the lower troposphere at Koror, Palau from 00:00 Z 14 August00:00 Z 16 August. During this time period, the sweet spot of the pre-typhoon Nuri disturbance is centered between 14.9 to $16.2 \mathrm{~N}$ and moves from 152.8 to $145.3 \mathrm{E}$. Therefore, the Guam sounding $(13.8 \mathrm{~N}, 144.5 \mathrm{E})$ is more representative of the conditions influencing the formation of Typhoon Nuri. These data (not shown) indicate deep easterly flow throughout the depth of the troposphere until 00:00 Z 15 August. After this period, a classical easterly wave signature is evident in the Guam sounding (which is corroborated by aircraft data) as low-level winds shift from NE-E-SE during 12:00 Z 15 August-00:00 Z 17 August. At no point does the Guam sounding data indicate the presence of low-level westerly flow extending into this region.

cast centers to identify an area of interest for collection of specialized observations or running model guidance (NHC, 2010). The designation of a system as an invest does not correspond to a likelihood of development (NHC, 2010). 

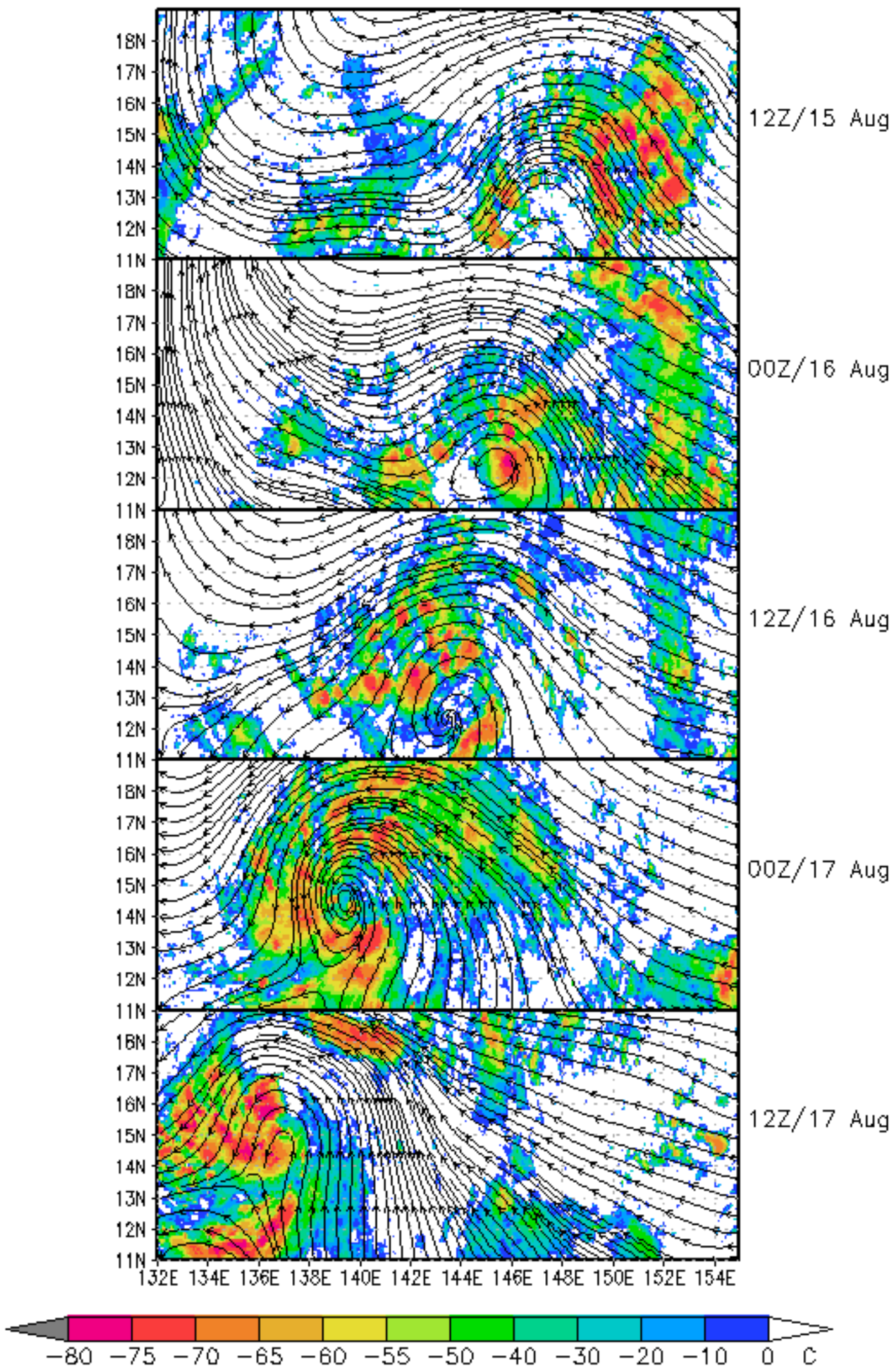

Fig. 10. Time series of GFS FNL $925 \mathrm{hPa}$ streamlines in the resting frame overlaid with MTSAT IR brightness temperature valid every $12 \mathrm{~h}$ from 12:00 Z 15 August to 12:00 Z 17 August. 

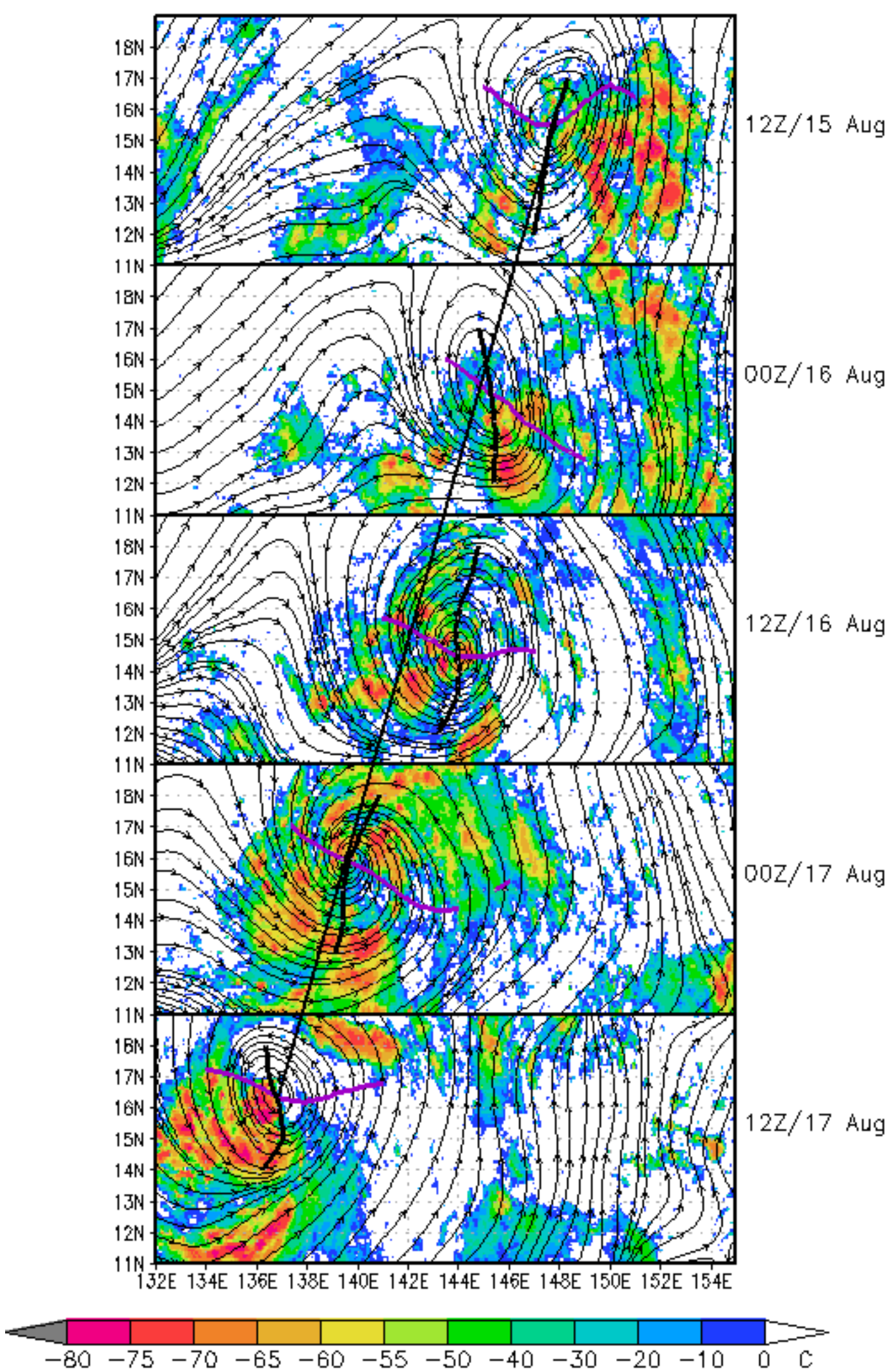

Fig. 11. Time series of GFS FNL $925 \mathrm{hPa}$ streamlines in the co-moving frame overlaid with MTSAT IR brightness temperature valid every $12 \mathrm{~h}$ from 12:00 Z 15 August to 12:00 Z 17 August. The black line represents the wave trough axis and the purple line the critical latitude as seen by the wave plus sub-synoptic scale flow. The thick black line indicates the propagation of the sweet spot. 


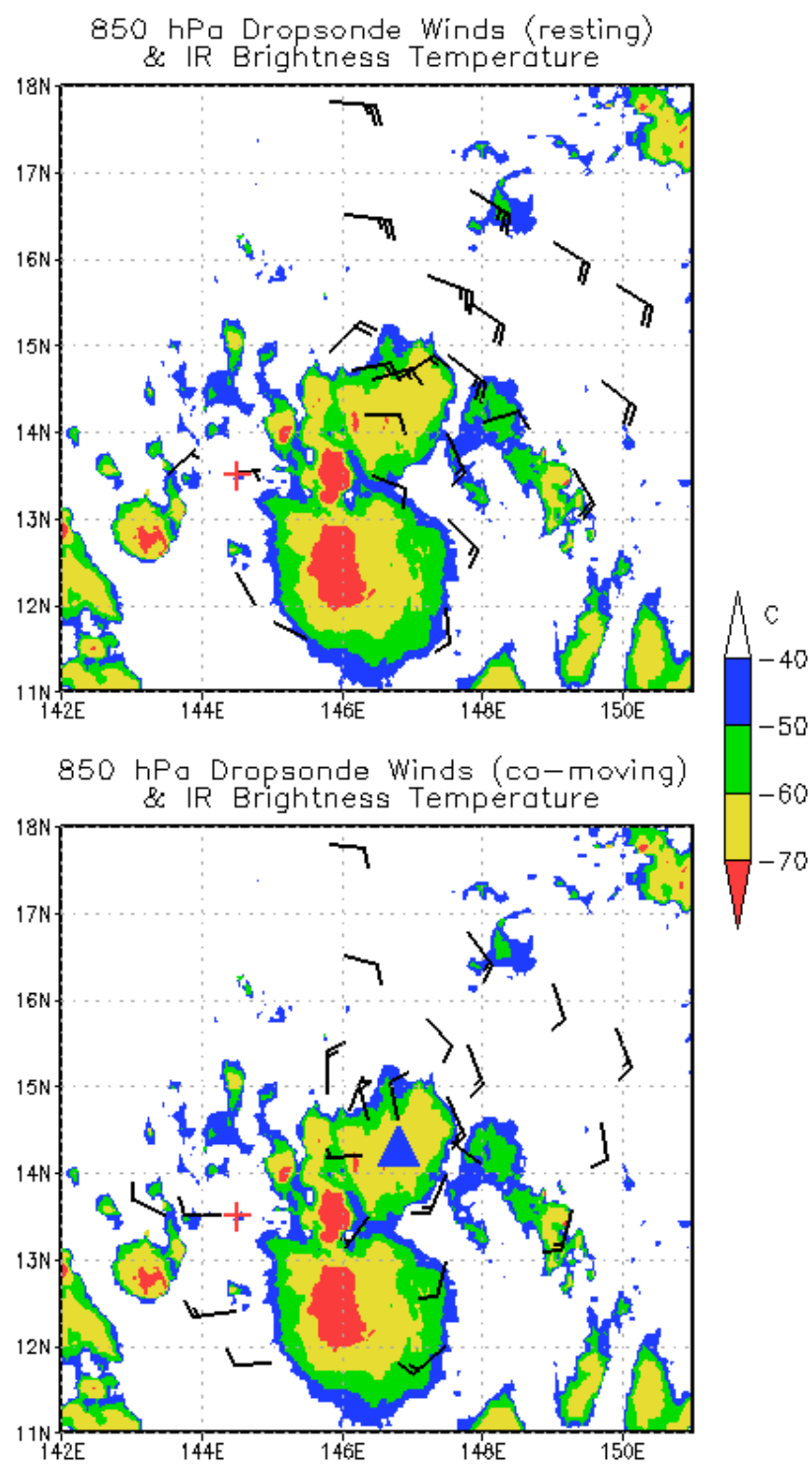

Fig. 12. Combined USAF C130 and NRL P3 $850 \mathrm{hPa}$ dropwindsonde observations from the first genesis flight centered on 00:00 Z 16 August overlaid with MTSAT IR data. Wind barbs are in the resting (top) and co-moving (bottom) frames. Wind speeds are in knots with a full barb representing $10 \mathrm{kt}$. There are no winds at the $850 \mathrm{hPa}$ level with a westerly wind component in the earth-relative frame. The red cross represents the location of Guam (the origin of the flights) and the blue triangle represents the approximate location of the low-level cyclonic circulation center in the co-moving frame. The $\mathrm{C} 130$ flight is centered along the wave trough axis and collected data throughout most of the pouch.

These data are corroborated by the spatial evolution of the observed wind field in both satellite-derived cloud-drift winds and QuikSCAT data. We have argued that 12:00 Z 15 August is a critical time in the tropical cyclogenesis sequence of Typhoon Nuri, as this coincides with the reintensification of convection within the marsupial pouch. The CIMSS low- level cloud drift winds prior to this time at 06:00 Z $15 \mathrm{Au}-$ gust (Fig. 15 top) and QuikSCAT surface wind data (Fig. 15 bottom) valid 15 August both show approximately uniform easterly flow from the dateline to points well west of $140 \mathrm{E}$ and north of $9 \mathrm{~N}$ (the solid red line demarcates the transition between easterly flow and westerly flow $)^{10}$. The westerly winds near Palau do not extend farther than 138E during the formation sequence. This confirms that large-scale westerly winds are not present in the area of the pre-Nuri disturbance (indicated by the red circle in Fig. 15); nor do they play any discernible role in the genesis of Typhoon Nuri. Examination of the CIMSS data for the period 00:00 Z 14-18Z 16 August (when JTWC upgrades the disturbance to a TD) confirms that synoptic-scale westerly flow is not observed farther east than 138E (below 20N) and corroborates the lack of a monsoonal flow in the vicinity of the pre-Nuri disturbance. On $16 \mathrm{Au}-$ gust both the QuikSCAT surface winds and GFS FNL data indicate the presence of isolated westerlies near the southeast portion of the wave in the resting frame. We suggest this is evidence of the wave forming a closed cyclonic circulation at the lower levels, rather than a large-scale, organized monsoon flow.

\subsubsection{The possible role of a TUTT}

It will be argued next that the presence of TUTT cells have no impact on the genesis of Typhoon Nuri. Two upper-level cyclonic circulations are identified by the CIMMS upper level cloud drift winds (not shown) in the general region of the pre-Nuri disturbance. The first was a weak, nearly stationary cyclonic circulation at $15 \mathrm{~N}, 160 \mathrm{E}$ present from 01:00 Z 14 August-21:00 Z 14 August. After this time, this circulation center drifts slightly south to $11 \mathrm{~N}$ and is present until 06Z 15 August. Subsequently, it is no longer distinguishable, as weak convection is initiated in the area. The second is a stronger upper-level cyclonic circulation that enteres the western North Pacific (28 N, 175 E) on 12:00Z 15 August. This TUTT moves southwest, eventually reaching $24 \mathrm{~N}$ 168 E by 00:00 Z 17 August. However, these upper-level cyclonic circulations observed in the CIMMS data are not believed responsible for the genesis of Typhoon Nuri. The first TUTT circulation is too weak and becomes indistinguishable as the genesis process began. The second TUTT, which represented a much better fit to Sadler's $(1976,1978)$ classical definition, is too far removed (approximately $19^{\circ}$ ) from the

10 The QuikSCAT data show a small area of isolated westerly winds located between 148E 8-9N on 15 August. These westerlies are spatially separated from the large-scale westerlies that extend through the Philippine Sea and northward. These westerly winds at 148 E 8-9 N are potentially signs of cross-equatorial flow extending into the developing low-level cyclonic circulation. They are not evidence of monsoonal flow impacting the genesis of Typhoon Nuri, as the flow is too limited in horizontal scale and not evident in the analysis prior to this time. 


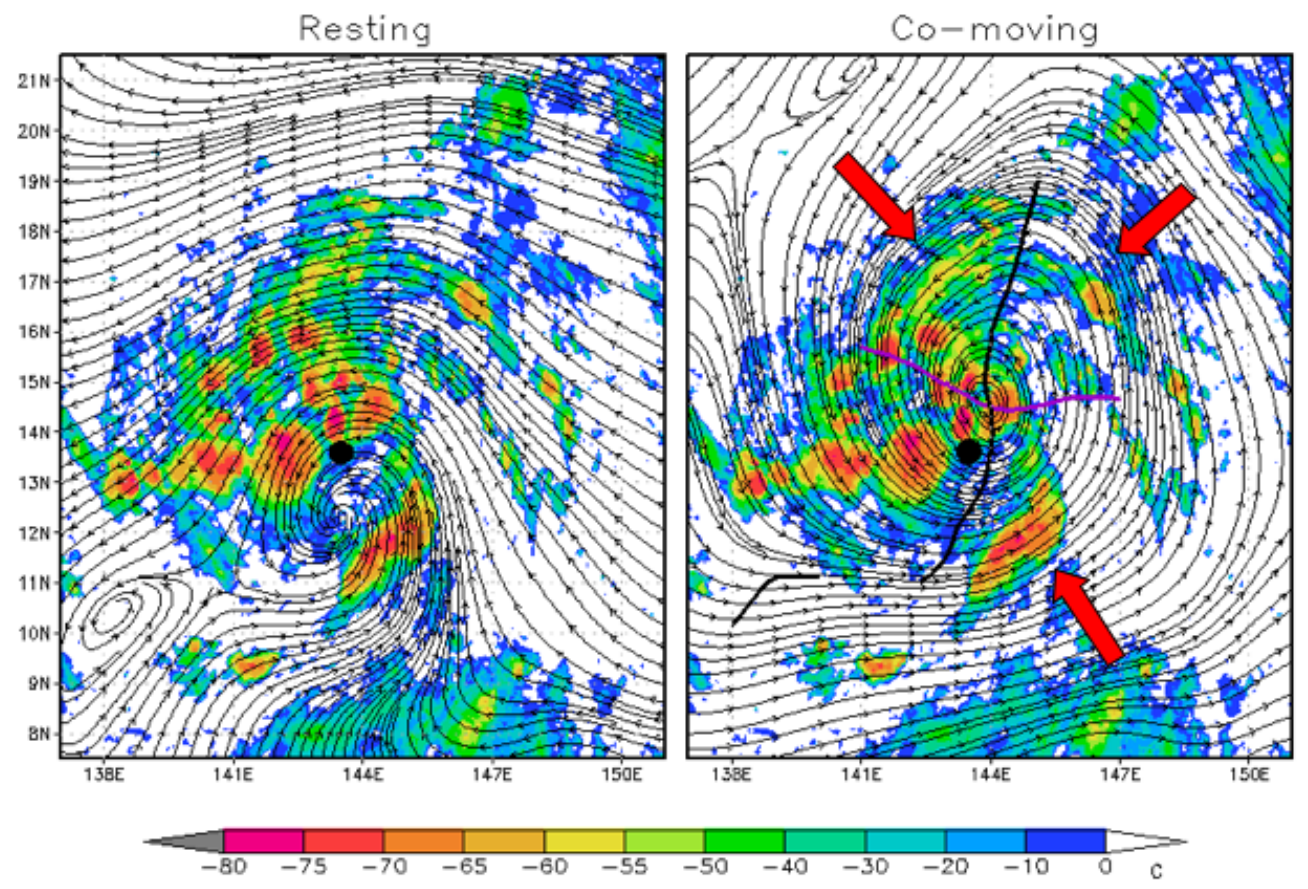

Fig. 13. GFS FNL $925 \mathrm{hPa}$ streamlines in the resting (left) and co-moving (right) frames overlaid with MTSAT IR brightness temperature valid 12:00 Z 16 August. In the co-moving frame, the black line represents the wave trough axis and the purple line the critical latitude. The red arrows indicate the convective bands spiraling cyclonically inward towards the sweet spot in the co-moving frame. The black dots represent the JTWC Best Track position.

genesis region to have any significant dynamical or thermodynamical influence on the pre-Nuri disturbance.

\subsection{Evaluation of real-time forecasts $(00: 00 \mathrm{Z}$ 11 August-12:00 Z 17 August)}

The construction of real-time forecasts incorporated in the methodology outlined in WMD09 was applied successfully during the TCS-08 field experiment in order to provide forecast guidance for operational flight planning. This methodology is based on the assumption that, while global forecast models currently are unable to represent the mesoscale processes in tropical cyclogenesis, they often do an adequate job capturing the synoptic-scale evolution. In the context of the marsupial paradigm, this suggests it is possible to track the easterly wave's critical layer and, moreover, predict the preferred location for tropical cyclogenesis to occur (WMD09), even in instances where tropical cyclogenesis is not predicted by the model. It is in this context that real-time "marsupial forecasts" can provide very useful information for the forecasting of tropical cyclogenesis.

Figure 16 depicts an example of the $\mathrm{T}+72 \mathrm{~h}$ NOGAPS (initial time: 12:00 Z 14 August) marsupial forecast valid at 12:00 Z 17 August (when the pre-Nuri disturbance is upgraded to a TS by JTWC). The left panel displays $925 \mathrm{hPa}$ streamlines in the co-moving frame along with OW, the critical latitude, and trough axis. The location of Guam is in- dicated by the red plus sign. The right hand side depicts vertical cross-sections of pouch diagnostics for OW, relative vorticity, and detrained volume flux. This forecast was used in the 15 August Daily Planning Meeting to make a go/no go decision for reconnaissance flights and was a significant factor in the decision to fly this disturbance.

At this forecast hour, all of the four global models used during TCS-08 (NOGAPS, GFS, ECMWF, UKMET) depict an easterly wave moving through the region (not shown). However, none develop the wave into a closed circulation in the earth-relative frame or a tropical cyclone at any validation time. The marsupial forecast product shown depicts a closed low-level cyclonic circulation (in the co-moving frame) along with a strong area of OW surrounding the sweet spot. This marsupial forecast predicts the favored region for genesis, should it occur, within $1.5^{\circ}$ latitude of the JTWC Best Track position ${ }^{11}$.

\footnotetext{
11 We have shown that operational numerical prediction models have the capability to predict genesis location in an operational environment using marsupial analysis methods. Although the success of these "marsupial forecasts" is dependent on the forecast skill of the global model, the diagnosis based on the "marsupial paradigm" provides additional insights to the standard model forecast. In the Nuri case, operational models did well in forecasting the favored latitude for genesis. However, the error in longitude was approximately $4^{\circ}$ for the $72-\mathrm{h}$ NOGAPS forecast, primarily due to the model's inaccurate representation of the propagation of the parent
} 

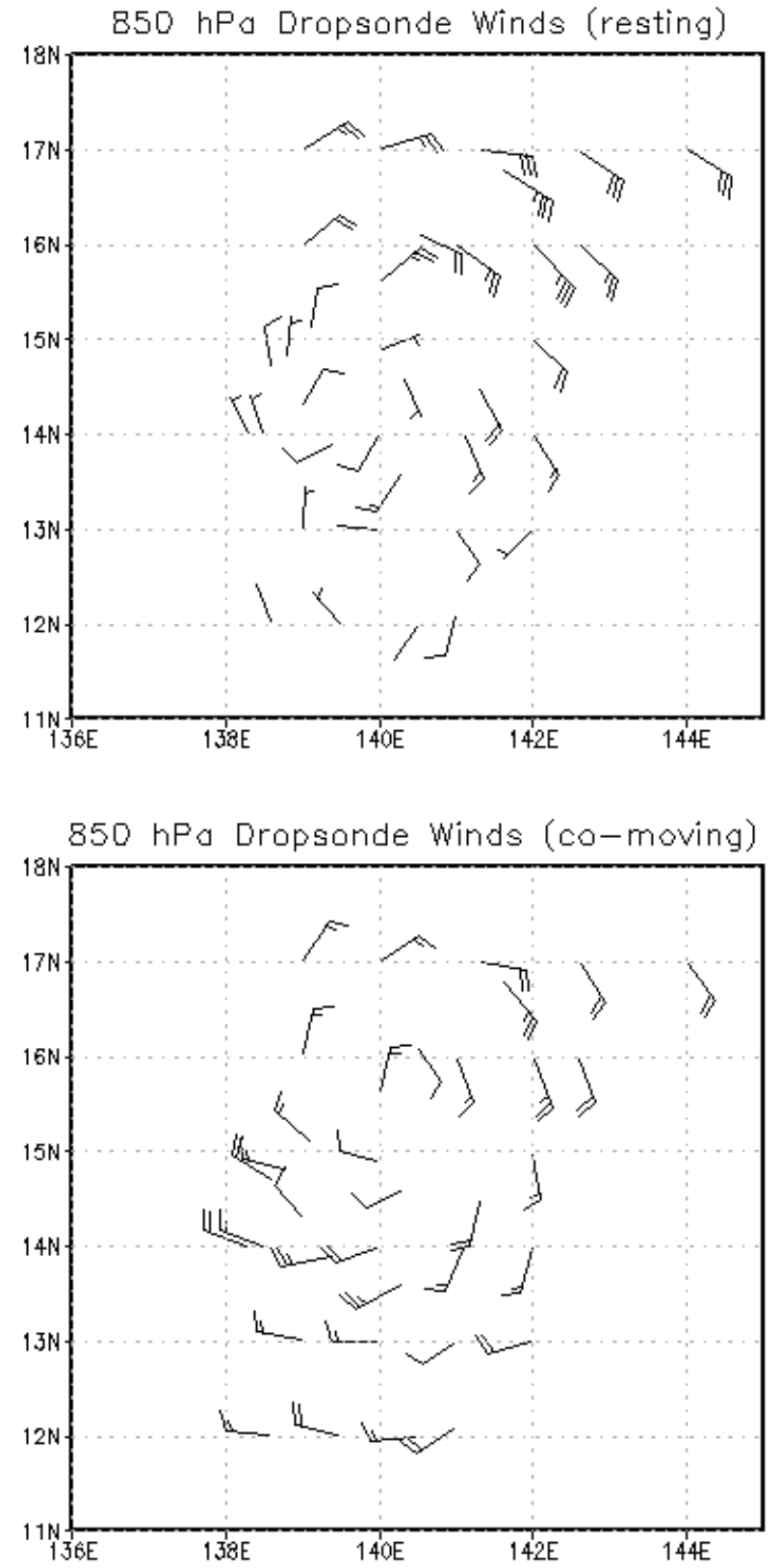

Fig. 14. Combined USAF C130 and NRL P3 $850 \mathrm{hPa}$ dropwindsonde observations from the second genesis flight centered on 00:00 Z 17 August in the resting (top) and co-moving frames (bottom). Wind speeds are in knots with a full barb representing $10 \mathrm{kt}$.

The model diagnostics (Fig. 16) predict low-level convergence around the genesis time, leading to an enhancement of low- to mid-level relative vorticity. The OW/relative vorticity plot shows an increase in both variables in the lower levels; variations in the two are qualitatively similar in the vertical (especially in the lower troposphere). This suggests that al-

easterly wave (due to errors in representing the background easterly flow).
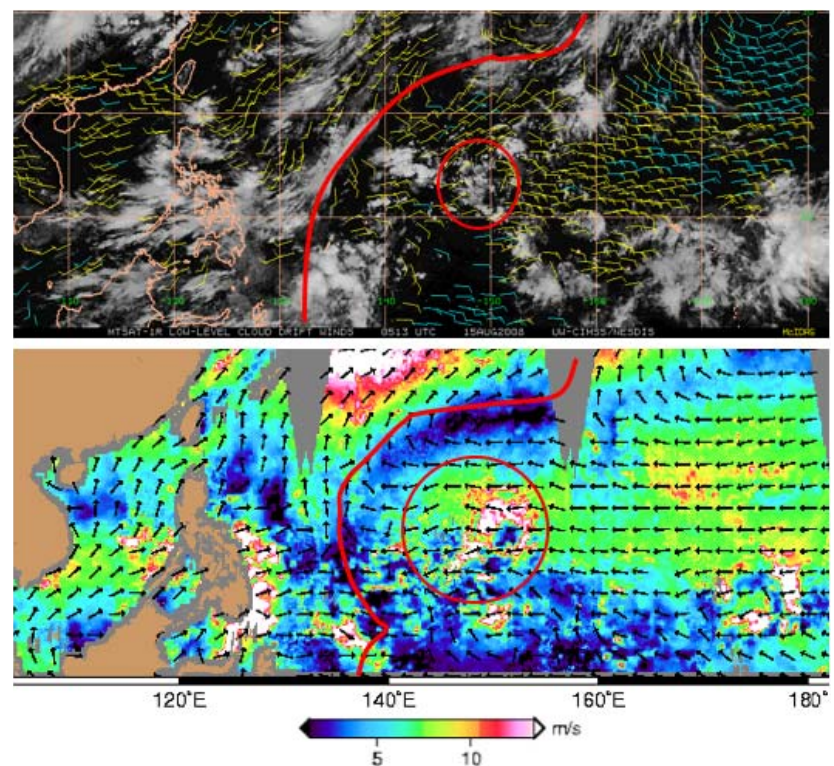

Fig. 15. CIMMS low-level cloud drift winds (top) valid 06:00 Z 15 August and QuikSCAT Level-3 retrieved wind vectors and wind speed (shaded) valid 15 August (bottom). The blue wind barbs in the CIMMS product are retrievals between the levels of 950 $851 \mathrm{hPa}$ and the yellow are retrievals between $850-700 \mathrm{hPa}$. The red circle highlights the easterly wave that is the precursor to Typhoon Nuri and the red line indicates the easternmost extent of large-scale organized westerly flow. Note that large-scale organized westerly winds are more than 10 degrees from the pre-Nuri disturbance in both analyses.

most all of the vorticity being produced is from the curvature rather than shear (in the co-moving frame), a favorable feature for tropical cyclogenesis (DMW09).

We believe that these pouch diagnostics have the potential to assist operational forecasters in easterly trade wind regimes because they offer the advantages of: i) a wavecentric viewpoint for diagnostic analyses, and ii) centering intense observations or satellite positioning around the preferred genesis location.

\section{Discussion}

JTWC began tracking the pre-Nuri disturbance at 00:00 Z 16 August with an initial center position of $146.8 \mathrm{E}, 13.2 \mathrm{~N}$ (Fig. 5), and it is classified as DB (depression beginning). At this time, the intersection of the GFS FNL ${ }^{12} 925 \mathrm{hPa}$ critical latitude and wave trough axis is located at $145.3 \mathrm{E}$,

\footnotetext{
${ }^{12}$ While there are certainly limitations to the GFS FNL (data assimilation, resolution, etc.), the GFS analysis is employed extensively here due to the limited amount of observational data available in the western North Pacific. The GFS FNL is in broad agreement when verified against observations. Furthermore, operational ECMWF and NOGAPS analyses provide a consistent evolutionary picture of the easterly wave and vorticity field from 7 August until
} 

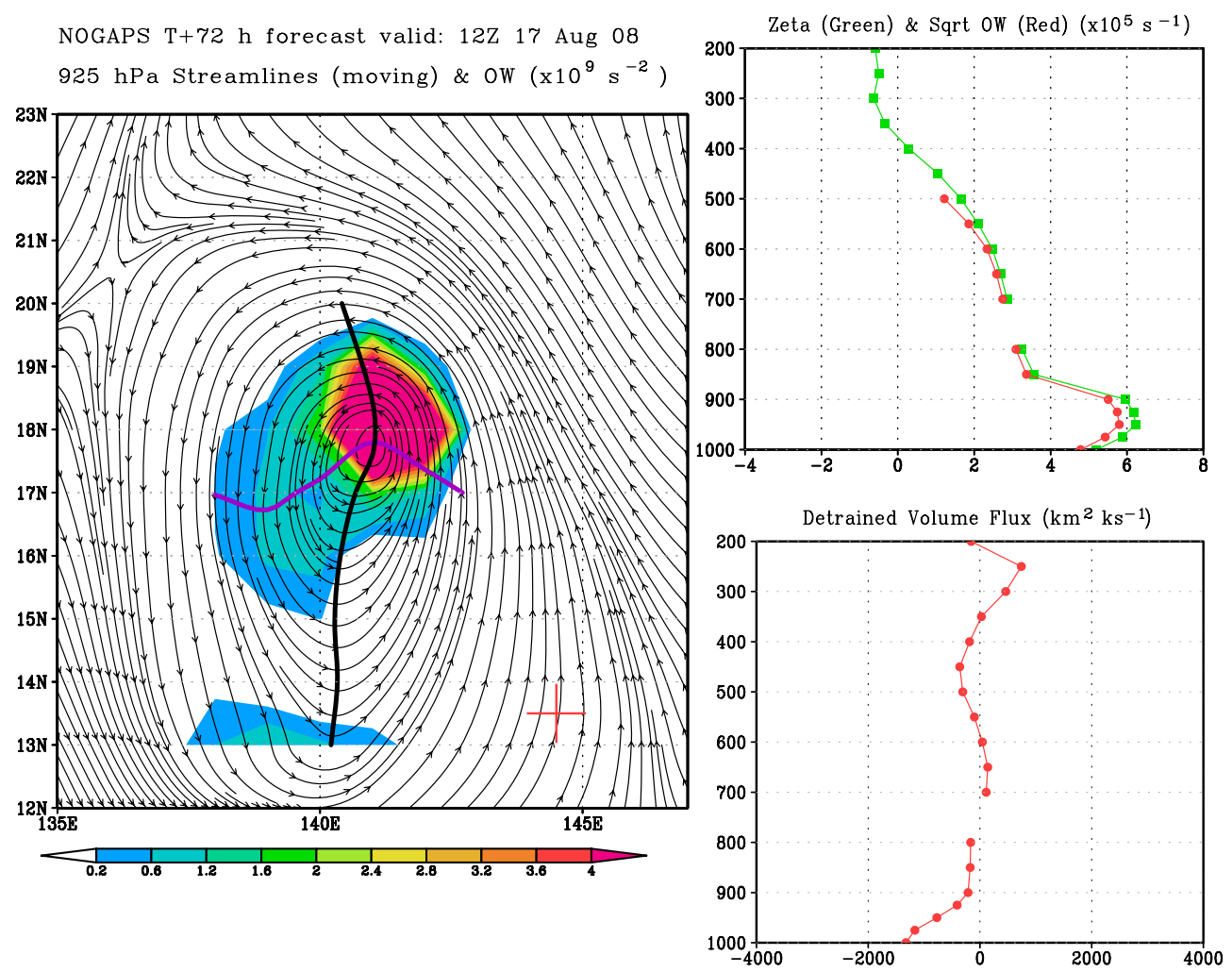

Fig. 16. Real-time 72-h NOGAPS forecast for the potential genesis of Typhoon Nuri. Model initialization time is 12:00 Z 14 August and is valid at 12:00 Z 17 August (time of TS declaration by JTWC). The left panel is $925 \mathrm{hPa}$ streamlines in the co-moving frame with OW (shaded), the wave trough (black line), critical latitude (purple line), and location of Guam (red plus). The right panels are area-averaged diagnostics calculated within a $3^{\circ} \times 3^{\circ}$ box moving with the wave's pouch so as to quantify the mesoscale nature of these variables within. The top right depicts area-averaged relative vorticity (green trace) and the area-averaged square root of OW (red trace). The bottom right is detrained volume flux as defined by Raymond et al. (1998). Unplotted data in the vertical profiles are due to missing model data at that level.

$14.9 \mathrm{~N}$. Twenty-four hours later, JTWC upgrades the developing storm to a TD centered at $140.2 \mathrm{E}, 14.8 \mathrm{~N}$, while the sweet spot is located at $139.7 \mathrm{E}, 15.9 \mathrm{~N}$. Finally, at 12:00 Z 17 August 2008, JTWC upgrades the TD to a TS located at $136.7 \mathrm{E}, 16.1 \mathrm{~N}$ while the sweet spot is at $136.8 \mathrm{E} 16.3 \mathrm{~N}$. Of particular interest to this study is the abrupt shift north in the JTWC Best Track between 00:00 Z and 06:00 Z 17 August. According to JTWC, the center of the developing TD shifts from $14.8 \mathrm{~N}$ to $16 \mathrm{~N}$ in the span of six hours, whereas it has shifted only 1.6 degrees north over the previous $36 \mathrm{~h}$. Furthermore, the position of the sweet spot varied by only 1.8 degrees in $36 \mathrm{~h}$ and remains well north of the JTWC Best Track position until TS declaration. These facts motivate the following question: Is this evidence of a sudden northward propagation of this disturbance, or a potential tracking error in the best track data?

genesis, which are broadly similar to the GFS FNL. These comparisons give us confidence that that the GFS FNL is representative of the synoptic-scale conditions leading up to the genesis of Typhoon Nuri.
As discussed in Sect. 3, on 00:00 Z 16 August (Fig. 11), the strongest convection associated with the pre-Nuri disturbance is located within the southern (and to a lesser extent the eastern) quadrant of the wave pouch. Figure 17 displays the GFS FNL from this time with $925 \mathrm{hPa}$ streamlines in the co-moving frame, OW (shaded), the wave trough axis (thick black line), critical latitude (purple line), and JTWC Best Track position (black circle). These data are consistent with satellite observations in that the OW maximum (and by proxy, the strongest vorticity and low-level convergence) is located in the southern portion of the pouch. With limited conceptual models and guidance on locating the center of a developing typhoon, declaring its position in the middle of the strongest convection and vorticity maximum is understandable ${ }^{13}$. However, deep tropical convection is generally chaotic and unpredictable (Nguyen et al., 2008). Further-

13 Although typhoon reconnaissance flights are typically not available in the western North Pacific, the JTWC Best Track data was influenced by the aircraft missions flown during TCS-08 because the potential low-level cyclonic circulations identified by the USAF C130 were incorporated into their best track determinations. 

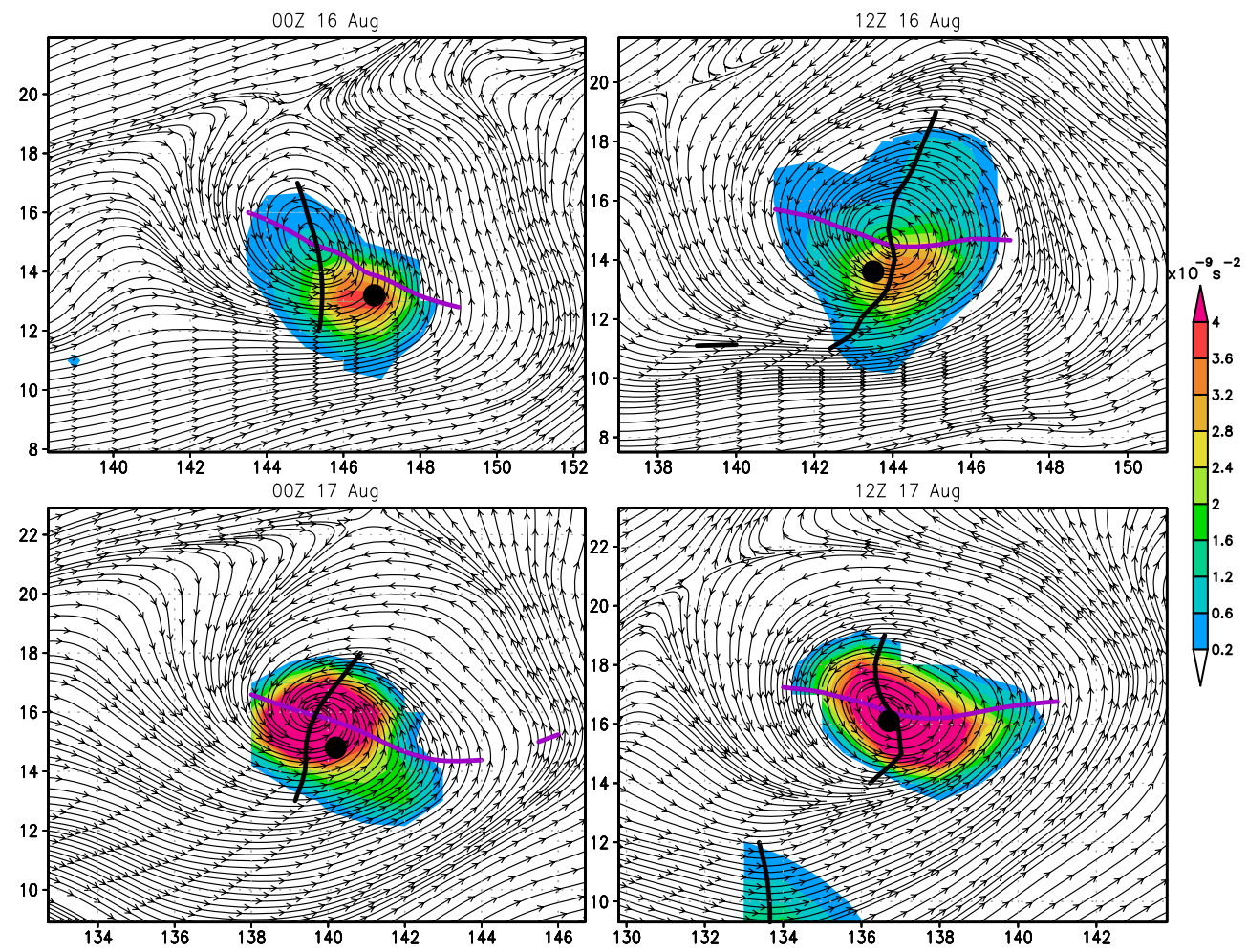

Fig. 17. Thirty-six hour (00:00 Z 16 August-12:00 Z 17 August) GFS FNL time series encapsulating the genesis phase of Typhoon Nuri. Thin black line are $925 \mathrm{hPa}$ streamlines in the co-moving frame, OW is shaded, the thick black line is the wave trough axis, and the purple line the critical latitude. The black dot indicates the JTWC Best Track position. The OW increases in intensity and centers on the sweet spot as genesis nears.

more, maxima in vorticity do not necessarily coincide with the emerging circulation center and small vorticity anomalies may be present throughout the pouch (Montgomery et al., 2010; Wang et al., 2010a, b).

By 12:00 Z 16 August the GFS FNL (Fig. 17) data shows an increase in the aerial coverage of $\mathrm{OW}$, as the higher OW values are now observed throughout most of the pouch. While the OW maximum remains in the southern quadrant, it has moved closer to the sweet spot. At this time, the IR data shows evidence of banded structures beginning to wrap around the sweet spot (red arrows in Fig. 13) ${ }^{14}$. When viewing this sequence in the resting frame (Fig. 13), the cyclonic circulation is farther south $(12.5 \mathrm{~N})$. The cloud features observed in the IR data appear to be a mass of convection primarily to the northwest of this center, rather than convective bands wrapping into a seedling tropical cyclone. Although this difference is subtle, it is important and provides evidence that the preferred region for genesis is the sweet spot at the northern portion of the wave, rather than the southern circulation. DMW09 suggest that the high frequency of storm formation occurred at or near the center of the translating gyre

14 While perhaps not transparent in the static images shown, movie loops of these satellite images suggest banded structures spiraling cyclonically inward toward the sweet spot. in almost all of the Atlantic cases they studied: “... seems almost uncanny and suggests to our minds an invisible 'guiding hand' from synoptic and meso- $\alpha$ scales". The so-called "guiding hand principle" is summarized therein:

"... whereas upscale aggregation of vorticity and its amplification by deep convection are essential to TC formation, they are not entirely responsible for the formation of a closed tropical depression in the first place. This formation is at least partly due to the dynamics of moist waves and involves a direct enstrophy cascade from larger synoptic-scale disturbances to mesoscale vorticity anomalies. This argument rests on the coherent relationship observed between the critical layers of tropical waves and tropical cyclogenesis events occurring in such regions".

Our initial analysis of the observational data in the Typhoon Nuri case suggests that this guiding hand principle is indeed at work. In Part II of this paper we will evaluate these concepts further through analysis of the mesoscale processes occurring within the pouch during Typhoon Nuri's genesis sequence.

AT 00:00 Z 17 August, the convection is more evenly distributed throughout the pouch (Fig. 11) and there is a significant area of banded convection to the northeast, wrapping around into the sweet spot. The GFS FNL OW maximum 


\section{Precip and $850 \mathrm{hPa}$ UV}
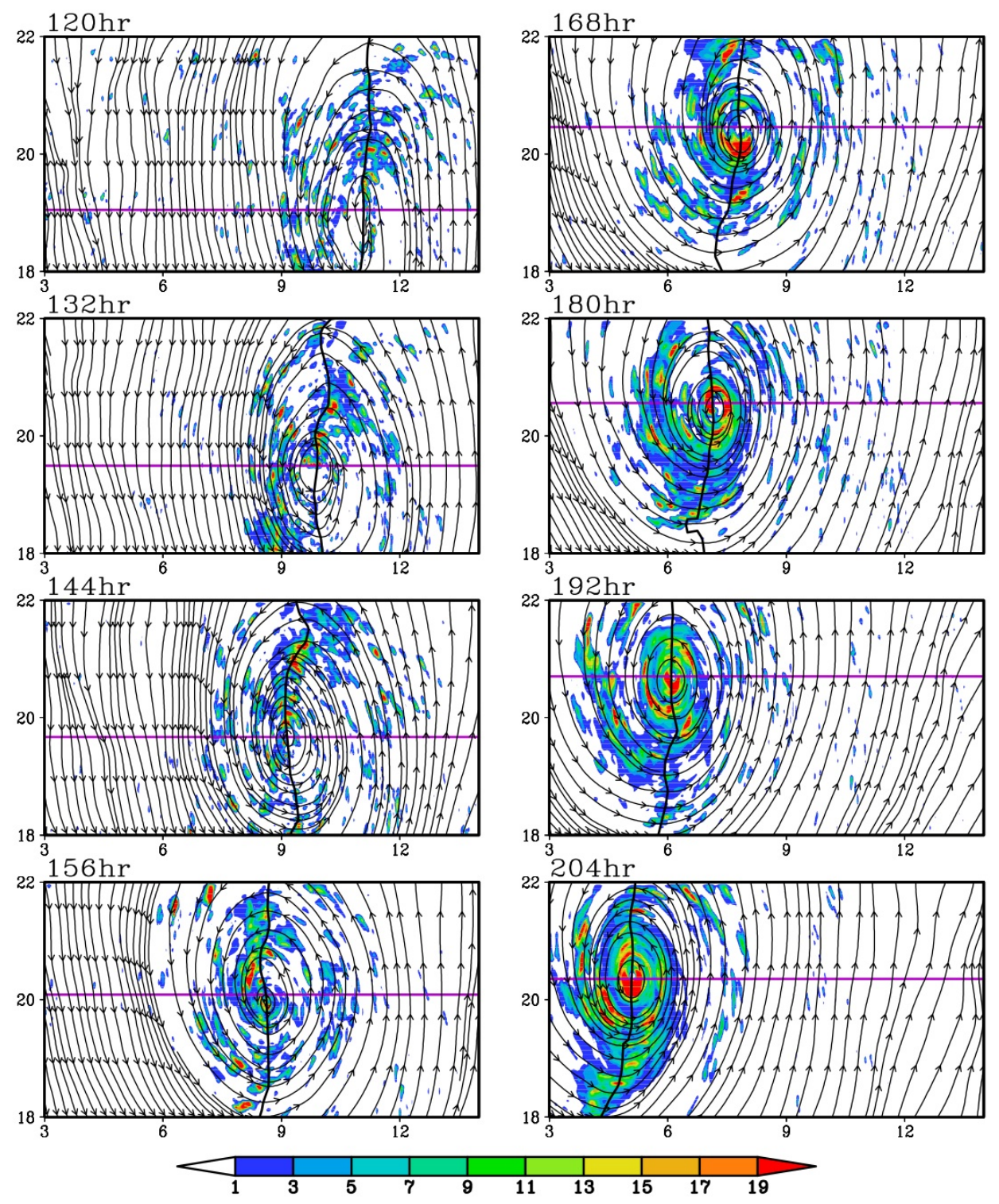

Fig. 18. Summary of idealized cloud-representing numerical simulation of the spatial and temporal evolution of precipitation within the critical layer of a developing easterly wave (see Montgomery et al., 2010 for details). The time series depicts surface rain rate (mm ${ }^{-1}$ ), $850 \mathrm{hPa}$ streamlines in the co-moving frame, the wave trough (thick black line), and critical latitude (purple line) at 12-h intervals beginning $120 \mathrm{~h}$ into the model run. The abscissa is longitude and the ordinate is latitude. The simulated evolution of precipitation is qualitatively consistent with the observed data in the pre-Nuri case.

has increased in aerial extent and intensity, and has organized around the center of the sweet spot (Fig. 17). At this point the JTWC Best Track position has the center at 14.8 N (Fig. 17), which appears to be close to the location of the strongest convection. However, it remains well south of the sweet spot and the OW maximum. By 12:00 Z 17 August (the time JTWC upgraded the disturbance to a TS) both centers are almost identical (Fig. 17). The OW has increased over the last $24 \mathrm{~h}$, consistent with the evolution seen in WMD09.
The evolution of convection described above is consistent with high-resolution idealized numerical simulations performed by Montgomery et al. (2010), which examines the transition of an easterly wave critical layer to a tropical storm. Figure 18 portrays an 84 -h time interval from said study of surface precipitation (explicitly resolved on the $3 \mathrm{~km}$ grid with warm-rain microphysics), $850 \mathrm{hPa}$ streamlines in the co-moving frame, the wave trough (black line), and critical latitude (purple line). For a complete descrip- 
tion of the model set-up, initial conditions, and physics, see Montgomery et al. (2010). The first three panels of this time series (120 h-144 h) depict light unorganized precipitation in all quadrants of the pouch with a maximum to the northeast (akin to the unorganized convection seen in the pre-Nuri disturbance prior to $12: 00 \mathrm{Z} 16$ August). By the $156 \mathrm{~h}$ time period, the precipitation structures are beginning to organize and banding features emerge. The $166 \mathrm{~h}$ time period shows organized bands wrapping around the sweet spot. The next three periods (180h-204h) show these banded structures spiraling into the sweet spot, an increase in the intensity of the precipitation, and heavy precipitation moving closer to the center and filing all quadrants of the wave's pouch. The evolution of the model-simulated precipitation is similar to that observed in Nuri in the sense that convection tends to be sustained near the sweet spot of the pouch.

On the basis of the evidence presented, these data strongly suggest that: i) the dynamical genesis sequence proposed by DMW09 can be useful for understanding the evolution of easterly waves in the western North Pacific basin. The juxtaposition of the closed cyclonic circulation in the co-moving frame and sweet spot in the GFS FNL is consistently farther north and shows a less abrupt shift than the center positions issued by JTWC. The evolution of banded features in the IR data and evolution of OW in GFS FNL strongly support the viewpoint that following this northern center is the simplest and superior way to track the pre-Nuri disturbance. ii) Deep convection alone should not be relied upon to identify the center of a developing tropical cyclone because deep convection is inherently chaotic and has been shown elsewhere to be an unreliable indicator of genesis location (DMW09). While OW and/or vorticity at the $850 \mathrm{hPa}$ level may be more robust, neither is as good as streamline (or streamfunction) analysis, which is superior for resolving the potential genesis location as shown by DMW09 and confirmed in this case. iii) Using the sweet spot model to track potential genesis locations should be a useful tool for identifying low-level cyclonic circulation centers operationally in the early genesis stages and may ultimately prove superior to methods being currently employed.

\section{Conclusions and future work}

This paper presents a first analysis of the tropical cyclogenesis of Typhoon Nuri that occurred in the western North Pacific basin during the TCS-08 field campaign. The basic state flow within which Typhoon Nuri formed is an easterly tradelike flow and the progenitor disturbance is an easterly wave that propagated approximately zonally over a ten-day interval with an earth-based zonal phase speed varying between $-10 \mathrm{~m} \mathrm{~s}^{-1}$ and $-7.0 \mathrm{~m} \mathrm{~s}^{-1}$. The observed phase speed, motion, and precipitation structure of the precursor disturbance are consistent with the structure of typical easterly waves studied in the western North Pacific basin dating as far back as Reed and Recker (1971). Given the easterly wave character of this formation event, it is considered a viable candidate for the marsupial paradigm proposed recently by DMW09. Evidence has been presented here in support of hypotheses H1-H3 of DMW09 for this Nuri case.

The following factors provide observational support of $\mathrm{H} 1$ in the tropical cyclogenesis sequence of Typhoon Nuri: i) convection, despite beginning in the southern quadrant of the pouch, remains largely within the pouch and becomes organized around the sweet spot as genesis nears. IR satellite imagery shows the beginning of banded convection around this location on 12:00 Z 16 August. ii) The dominant circulation that emerges as Typhoon Nuri is located within the highly vortical region of the wave's cat's eye circulation near the intersection of the wave trough and the critical latitude (confirmed by GFS FNL and IR satellite data).

Similarly, in the case of H2: i) the GFS FNL identifies a set of closed streamlines in a translating frame of reference representing the wave's pouch. This pouch is evident approximately nine days prior to formation. The pouch significantly weakens as it traverses through a hostile environment, and then re-emerges as a coherent circulation two days prior to TS declaration. ii) The reinvigoration of convection at 12:00 Z 15 August occurs largely within the pouch and we suggest is most likely triggered by an area of higher HHC and vorticity located in the southern quadrant of the pouch. Over the next $36 \mathrm{~h}$, the deep convection becomes more vigorous and the CIMMS TPW analysis suggests continual moistening of the column. iii) CIMMS TPW analysis shows also that the dry air surrounding the pouch moves approximately in the same background flow as the moist air within it. Despite surrounding it on three sides, little if any of this air appears to enter the pouch (consistent with the increase in TPW). iv) Whereas the strong environmental vertical wind shear may have temporarily decreased the vertical coherence of the pouch and temporarily stalled genesis, the critical layer evidently remains resilient enough to keep the low- to midlevel proto-vortex intact until it is able to enter a more favorable environment. In this regard, the tropical cyclogenesis sequence of Typhoon Nuri seems to provide a useful illustration of the marsupial paradigm. In a conducive environment, the vertical extent of the pouch as captured in the analysis data is able to extend upward. The apparent upward growth of the pouch is hypothesized to be due to persistent deep convection within and the low- to mid-level convergence of ambient cyclonic vorticity that would accompany a predominantly convective mass-flux profile. When the local vertical shear increases significantly, the organization process seems to stall, yet, the low-level moisture remains protected within the pouch. Once the vertical shear weakens for an extended period of time, the pouch again extends upwards with time in conjunction with enhanced mid-level moisture.

The tracking of the parent easterly wave disturbance for 10 days and the maintenance of its structure as it propagates through a hostile environment are consistent with the third 
hypothesis H3 of DMW09. It is conceivable that the easterly wave is enhanced by the presence of diabatically amplified eddies within the pouch and that this hybrid wave-vortex system maintained its coherence and eventually strengthened through this symbiotic interaction.

Following the forecast and diagnostic techniques outlined by WMD09, real-time marsupial forecasts were produced in support of TCS-08 operations that were able to predict the latitude of tropical cyclone development out to $72 \mathrm{~h}$ within $1.5^{\circ}$. These forecasts provided useful insight that raw operational numerical model data could not. As an example, none of the four forecast models used in the experiment predicted a closed low-level cyclonic circulation in the earthbased frame of reference.

While a wealth of data has been presented herein to suggest that the marsupial way of thinking can be a useful forecaster/diagnostic tool in the western North Pacific basin during easterly trade wind regimes, much work remains to be done. At the synoptic and sub-synoptic (meso- $\alpha$ ) scales, the data presented herein does support the tropical cyclogenesis sequence hypothesized by DMW09. The specific mesoscale pathway to the emergent tropical cyclone vortex has yet to be elucidated for this case, however. The first hypothesis of DMW09 (H1) states: "This multi-scale interaction provides a dynamical pathway to "bottom-up" development of the proto-vortex from below". The "bottom-up" pathway to tropical cyclogenesis suggested by Montgomery and colleagues (e.g., Montgomery and Enagonio, 1998; Hendricks et al., 2004; Montgomery et al., 2006) postulates that rotating convective cells called vortical hot towers (VHTs) drive the development of the tropical cyclone vortex via low-level convergence and near-surface vorticity spin up that leads the spin up at all levels. The near-surface vorticity anomalies observed in these numerical simulations tend to be collected at low-levels by the diabatically-forced overturning circulation; these vorticity anomalies undergo also a diabatic vortex merger process during active convection or adiabatic merger and vortex axisymmetrization when convection has subsided. Part II of this paper will examine aspects of the mesoscale development within the pouch of the pre-Nuri disturbance. Specifically, properties of the convection and kinematic flow observed within the pouch will be evaluated using the data from the ELDORA radar in order to assess the contribution of VHTs to the spin up of the meso-beta scale tropical cyclone vortex. Aircraft flight level data, SFMR data, and additional remote sensing data including microwave imagery and ground-based Doppler radar will be used to augment the analysis presented here and further scrutinize the mesoscale evolution of Typhoon Nuri's tropical cyclogenesis sequence.

\section{Appendix A}

\section{List of acronyms}

\begin{tabular}{|c|c|}
\hline AXBT & $\begin{array}{l}\text { Airborne Expendable Bathometry } \\
\text { Thermograph }\end{array}$ \\
\hline CIMMS & $\begin{array}{l}\text { Cooperative Institute for Meteorological } \\
\text { Satellite Services, University of Wisconsin }\end{array}$ \\
\hline DB & Depression Beginning \\
\hline ELDORA & Electra Doppler Radar \\
\hline ECMWF & $\begin{array}{l}\text { European Center for Medium-range Weather } \\
\text { Forecasts }\end{array}$ \\
\hline ERA-40 & ECMWF Reanalysis Data \\
\hline GFS FNL & Global Forecast System Final Analysis \\
\hline $\mathrm{HHC}$ & Oceanic Hurricane Heat Content \\
\hline IR & Infrared \\
\hline ITCZ & Intertropical Convergence Zone \\
\hline JTWC & Joint Typhoon Warning Center \\
\hline MTSAT & Multi-Functional Transport Satellite \\
\hline NASA & $\begin{array}{l}\text { National Aeronautics and Space } \\
\text { Administration }\end{array}$ \\
\hline $\mathrm{NHC}$ & National Hurricane Center \\
\hline NOGAPS & $\begin{array}{l}\text { Naval Operational Global Atmospheric } \\
\text { Prediction System }\end{array}$ \\
\hline NRL & Naval Research Laboratory \\
\hline OW & Okubo-Weiss Parameter \\
\hline SFMR & Stepped Frequency Microwave Radiometer \\
\hline $\mathrm{TD}$ & Tropical Depression \\
\hline TCS-08 & Tropical Cyclone Structure 2008 \\
\hline TPW & Total Precipitable Water \\
\hline TRMM & Tropical Rainfall Measurement Mission \\
\hline TS & Tropical Storm \\
\hline TUTT & Tropical Upper Tropospheric Trough \\
\hline UKMET & United Kingdom Meteorological Office \\
\hline USAF & United States Air Force \\
\hline VHT & Vortical Hot Tower \\
\hline
\end{tabular}

Acknowledgements. Thanks to CIMMS and NASA for satellite data and NRL Stennis for ocean data. This research was supported in part by the National Science Foundation Grants ATM-0733380, ATM-0715426, ATM-0649946, the Office of Naval Research grant N001408WR20129 and by the US Naval Postgraduate School in Monterey, California. This work was initiated between daily planning meetings and research flights while in the field on Guam, and a "zero draft" was completed soon after at the Naval Postgraduate School (NPS). We would like to thank R. Ferek, the ONR/NSF-supported scientists (especially Pat Harr, Russ Elsberry of the NPS and Peter Black of NRL/Monterey), the professional and student forecasters, the flight crews and support personnel who worked tirelessly to make the field campaign a great success. The science team fostered a stimulating atmosphere for conducting tropical cyclone research. Finally, we would like to thank Drs. John Molinari, Roger Smith and George Kiladis for providing constructive reviews that helped us improve the manuscript.

Edited by: P. Haynes 


\section{References}

Carr III, L. E. and Elsberry, R. L.: Monsoonal interactions leading to sudden tropical cyclone track changes, Mon. Weather Rev., 123, 265-290, 1995.

Chang, C. P., Morris, V. F., and Wallace, J. M.: A statistical study of easterly waves in the western Pacific: July-December 1964, J. Atmos. Sci., 27, 195-201, 1970.

Chen, T. C., Wang, S. Y., Yen, M. C., and Clark, A. J.: Are tropical cyclones less effectively formed by easterly waves in the western North Pacific than in the North Atlantic?, Mon. Weather Rev., 136, 4527-4540, 2008.

Deleon, R. P.: The role of subtropical intrusion in the development of Typhoon Usagi (5W) 2007. MS Thesis, Naval Postgraduate School, Monterey, CA, 118pp, 2008.

Dickinson, M. and Molinari, J.: Mixed Rossby-gravity waves and western Pacific tropical cyclogenesis. Part I: Synoptic evolution, J. Atmos. Sci., 59, 2183-2196, 2002.

Dunkerton, T. J., Montgomery, M. T., and Wang, Z.: Tropical cyclogenesis in a tropical wave critical layer: easterly waves, Atmos. Chem. Phys., 9, 5587-5646, doi:10.5194/acp-9-5587-2009, 2009.

Elsberry, R. L. and Harr, P. A.: Tropical Cyclone Structure (TCS08) field experiment science Basis, observational platforms, and strategy, Asia-Pac. J. Atmos. Sci., 44, 209-231, 2008.

Ferreira, R. N. and Schubert, W. H.: Barotropic aspects of ITCZ breakdown, J. Atmos. Sci., 54, 261-285, 1997.

Frank, N. L.: Atlantic tropical systems of 1969. Mon. Weather Rev., 98, 307-314, 1970.

Frank, W. M. and Roundy, P. E.: The Role of Tropical Waves in Tropical Cyclogenesis, Mon. Weather Rev., 134, 2397-2417, 2006.

Fu, B., T. Li, M. S. Peng, and F. Weng: Analysis of Tropical Cyclogenesis in the Western North Pacific for 2000 and 2001. Weather Forecast., 22, 763-780, 2007.

Glickman, T. S.: Glossary of Meteorology, American Meteorological Society Boston, USA, 850 pp., 2000.

Gray, W. M.: Global view of the origin of tropical disturbances and storms. Mon. Weather Rev., 96, 669-700, 1968.

Gray, W. M.: Tropical cyclone genesis. Department of Atmos. Sci. Paper No. 323, Colorado State University, Fort Collins, CO, USA, 121 pp., 1975.

Harr, P. A., Elsberry, R. L., and Chan, J. C. L.: Transformation of a large monsoon depression to a tropical storm during TCM-93, Mon. Weather Rev., 124, 2625-2643, 1996.

Hendricks, E. A., Montgomery, M. T., and Davis, C. A.: The role of "vortical" hot towers in the formation of tropical cyclone Diana (1984). J. Atmos. Sci., 61, 1209-1232, 2004.

Holland, G.: Scale interaction in the western Pacific monsoon, Meteorol. Atmos. Phys., 56, 57-79, 1995.

Jones, S. C.: The evolution of vortices in vertical shear: Initially barotropic vortices. Q. J. Roy. Meteor. Soc., 121, 821-851, 1995.

Lander, M. A.: Description of a monsoon gyre and its effects on the tropical cyclones in the western North Pacific during August 1991, Weather Forecast., 9, 640-654, 1994.

Leipper, D. and D. Volgenau: Hurricane heat potential of the Gulf of Mexico. J. Phys. Oceanogr., 2, 218-224, 1972.

Lussier III, L. L.: A Multi-Scale Analysis of Tropical Cyclogenesis within the Critical Layer of Tropical Easterly Waves in the Atlantic and Western North Pacific Sectors, PhD Dissertation,
Naval Postgraduate School, Monterey, CA, USA, 245 pp., 2010.

Molinari, J.: Paradigms of tropical cyclogenesis, B. Am. Meteorol. Soc., 85, 662-663, 2004.

Montgomery, M. T. and Enagonio, J.: Tropical cyclogenesis via convectively forced vortex Rossby waves in a three-dimensional quasigeostrophic model, J. Atmos. Sci., 55, 3176-3207, 1998.

Montgomery, M. T., Nicholls, M. E., Cram, T. A., and Saunders, A. B.: A vortical hot tower route to tropical cyclogenesis, J. Atmos. Sci., 63, 355-386, 2006.

Montgomery, M. T., Wang, Z., and Dunkerton, T. J.: Intermediate and high resolution numerical simulations of the transition of a tropical wave critical layer to a tropical storm, Atmos. Chem. Phys., in press, 2010.

National Hurricane Center (NHC): online available at: http://www. nhc.noaa.gov/aboutgloss.shtml, 2010.

Neumann, C. J.: Global overview. Global Guide to Tropical Cyclone Forecasting, World Meteor. Org, 1-1.56, 1993.

Nguyen, V. S., R. K. Smith, and M. T. Montgomery: Tropical cyclone intensification and predictability in three dimensions, Quart. J. Roy. Meteor. Soc., 134, 563-582, 2008.

Raymond, D. J., Lopez-Carrillo, C., and Lopez Cavazos, L.: Casestudies of developing east Pacific easterly waves, Q. J. Roy. Meteor. Soc., 124, 2005-2034, 1998.

Reasor, P. D., Montgomery, M. T., and Grasso, L. D.: A new look at the problem of tropical cyclones in vertical shear flow: Vortex resiliency, J. Atmos.Sci., 61, 3-22, 2004.

Reasor, P. D. and Montgomery, M. T.: Three-dimensional alignment and corotation of weak, TC-like vortices via linear vortex Rossby waves, J. Atmos. Sci., 58, 2306-2330, 2001.

Reed, R. J. and Recker, E. E.: Structure and properties of synopticscale wave disturbances in the equatorial western Pacific, J. Atmos. Sci., 28, 1117-1133, 1971.

Ritchie, E. A. and Holland, G. J.: Large-scale patterns associated with tropical cyclogenesis in the western Pacific, Mon. Weather Rev., 127, 2027-2043, 1999.

Sadler, J. C.: A role of the tropical upper tropospheric trough in early season typhoon development, Mon. Weather Rev., 104, 1266-1278, 1976.

Sadler, J. C.: Mid-season typhoon development and intensity changes and the tropical upper tropospheric trough. Mon. Weather Rev., 106, 1137-1152, 1978.

Schecter, D. A., Montgomery, M. T., and Reasor, P. D.: A theory for the vertical alignment of a quasigeostrophic vortex, J. Atmos. Sci, 59, 150-168, 2002.

Schecter, D. A. and Montgomery, M. T.: Waves in a cloudy vortex, J. Atmos. Sci., 64, 314-337, 2007.

Schecter, D. A.: The spontaneous imbalance of an atmospheric vortex at high Rossby number, J. Atmos. Sci., 65, 2498-2521, 2008.

Serra, Y. L., Kiladis, G. N., and Cronin, M. F.: Horizontal and Vertical Structure of Easterly Waves in the Pacific ITCZ, J. Atmos. Sci., 65, 1266-1284, 2008.

Wang, C. and Magnusdottir, G.: The ITCZ in the central and eastern Pacific on synoptic time scales, Mon. Weather Rev., 134, 14051421, 2006.

Wang, Z., Montgomery, M. T., and T. J. Dunkerton: A dynamicallybased method for forecasting tropical cyclogenesis location in the Atlantic sector using global model products, Geophys. Res. Lett., 36, L03801, doi:10.1029/2008GL035586, 2009. 
Wang, Z., Montgomery, M. T., and Dunkerton, T. J.: Genesis of Pre-hurricane Felix (2007). Part I: The role of the easterly wave critical layer, J. Atmos. Sci., 67, 1711-1729, 2010a.
Wang, Z., Montgomery, M. T., and Dunkerton, T. J.: Genesis of Prehurricane Felix (2007). Part II: Warm core formation, precipitation evolution and predictability, J. Atmos. Sci., 67, 1730-1744, 2010b. 